NBER WORKING PAPER SERIES

\title{
IMPLICATIONS OF AN ECONOMIC THEORY OF CONFLICT: HINDU-MUSLIM VIOLENCE IN INDIA
}

\author{
Anirban Mitra \\ Debraj Ray \\ Working Paper 19090 \\ http://www.nber.org/papers/w19090
NATIONAL BUREAU OF ECONOMIC RESEARCH
1050 Massachusetts Avenue
Cambridge, MA 02138 \\ May 2013
}

Ray is grateful for funding from the National Science Foundation (SES-1261560), the Fulbright Foundation and for hospitality from the Indian Statistical Institute during a year of leave from NYU. Thanks to Abhijit Banerjee, V. Bhaskar, Sam Bowles, Sugato Dasgupta, Oeindrila Dube, Joan Esteban, Mukesh Eswaran, Raji Jayaraman, David Ludden, Michael Manove, Kalle Moene, Andrew Oswald and Rohini Pande for useful discussions, and to Steve Wilkinson for granting us access to a dataset on religious conflict. We thank Jay Dev Dubey for his able research assistance. We are grateful to five anonymous referees for their valuable comments. We particularly thank Co-Editor Jesse Shapiro, who went beyond the call of duty in his detailed reading of the manuscript, making many constructive suggestions that greatly improved both the content and the exposition. The views expressed herein are those of the authors and do not necessarily reflect the views of the National Bureau of Economic Research.

NBER working papers are circulated for discussion and comment purposes. They have not been peerreviewed or been subject to the review by the NBER Board of Directors that accompanies official NBER publications.

(C) 2013 by Anirban Mitra and Debraj Ray. All rights reserved. Short sections of text, not to exceed two paragraphs, may be quoted without explicit permission provided that full credit, including $\mathbb{C}$ notice, is given to the source. 
Implications of an Economic Theory of Conflict: Hindu-Muslim Violence in India Anirban Mitra and Debraj Ray

NBER Working Paper No. 19090

May 2013, Revised January 2014

JEL No. O15,O43,O53

\title{
ABSTRACT
}

We model inter-group conflict driven by economic changes within groups. We show that if group incomes are low, increasing group incomes raises violence against that group, and lowers violence generated by it. We then apply the model to data on Hindu-Muslim violence in India. Our main result is that an increase in per-capita Muslim expenditures generates a large and significant increase in future religious conflict. An increase in Hindu expenditures has negative or no effect. These findings speak to the origins of Hindu-Muslim violence in post-Independence India.

\author{
Anirban Mitra \\ Department of Economics \\ University of Oslo \\ Postboks 1095 Blindern 0317 OSLO \\ Norway \\ anirban.mitra@econ.uio.no \\ Debraj Ray \\ Department of Economics \\ New York University \\ 19 West Fourth Street \\ New York, NY 10003 \\ and NBER \\ debraj.ray@nyu.edu
}




\title{
IMPLICATIONS OF AN ECONOMIC THEORY OF CONFLICT:
}

\author{
Hindu-Muslim Violence in India
}

\author{
By ANIRBAN Mitra AND DEBRAJ RAY ${ }^{1}$ \\ August 2012, revised December 2013
}

\begin{abstract}
We model inter-group conflict driven by economic changes within groups. We show that if group incomes are low, increasing group incomes raises violence against that group, and lowers violence generated by it. We then apply the model to data on Hindu-Muslim violence in India. Our main result is that an increase in per-capita Muslim expenditures generates a large and significant increase in future religious conflict. An increase in Hindu expenditures has negative or no effect. These findings speak to the origins of Hindu-Muslim violence in post-Independence India.
\end{abstract}

\section{Journal of Economic Literature Classification Numbers: C33, D31, D74.}

Keywords: Conflict, income distribution, religious violence, uneven growth.

\section{INTRODUCTION}

We study Hindu-Muslim conflict in post-Independence India through the lens of economics. We allow for two channels that link economics to conflict. Under the first, Hindu-Muslim violence is the systematic use of a particular marker (religion, in this case) for appropriating economic surplus, either directly through resource-grabbing or looting, or indirectly through exclusion from jobs, businesses or property. Under the second, existing inter-group hatreds are re-ignited or exacerbated by economic progress within one of the groups. Both approaches have the same formal representation, which makes robust predictions regarding the effect of group incomes on intergroup violence. We examine these predictions empirically.

The recurrent episodes of Hindu-Muslim conflict in India (going back to Partition and earlier) form the motivation for this paper. Even if we exclude the enormity of human losses from religious violence during Partition, such conflict has continued through the second half of the twentieth century, accounting for over 7,000 deaths over 1950-2000. There is reason to believe that the situation may not have changed much since: witness, for instance, the rampant Hindu-Muslim violence unleashed in the Indian state of Gujarat in 2002. It may be argued that these numbers are small relative to the overall population of India. From a pure arithmetical perspective they are,

\footnotetext{
${ }^{1}$ Mitra: University of Oslo; Ray: New York University. Ray is grateful for funding from the National Science Foundation (SES-1261560), the Fulbright Foundation and for hospitality from the Indian Statistical Institute during a year of leave from NYU. Thanks to Abhijit Banerjee, V. Bhaskar, Sam Bowles, Sugato Dasgupta, Oeindrila Dube, Joan Esteban, Mukesh Eswaran, Raji Jayaraman, David Ludden, Michael Manove, Kalle Moene, Andrew Oswald and Rohini Pande for useful discussions, and to Steve Wilkinson for granting us access to a dataset on religious conflict. We thank Jay Dev Dubey for his able research assistance. We are grateful to five anonymous referees for their valuable comments. We particularly thank Co-Editor Jesse Shapiro, who went beyond the call of duty in his detailed reading of the manuscript, making many constructive suggestions that greatly improved both the content and the exposition.
} 
but they do not capture the less measurable consequences of conflict: displacement, insecurity, segregation, loss of livelihood, widespread fear and the sapping of the morale of an entire society.

Like the many episodes of ethnic violence that have occurred all around the world, it is prima facie reasonable that there is an economic component to Hindu-Muslim conflict. There is, of course, no getting away from the facts of sheer hatred and mistrust, or what one might call the "primordialist explanations" for ethnic violence. Nor does one necessarily need to get away from primordialism, provided that we entertain the possibility that the economic progress of one's enemies may heighten the resentment and spite that one feels. But equally, there could be the systematic use of violence for economic gain, for the control - via appropriation or systematic exclusion - of property, occupations, business activity and resources (see, e.g., Das (1992), André and Platteau (1998), Collier and Hoeffler (1998, 2004), Dube and Vargas (2013), Field, Levinson, Pande and Visaria (2008), Iyer and Do (2009) and the recent survey by Blattman and Miguel (2010)). This economic perspective is no contradiction to the use of noneconomic markers (such as religion) in conflict. ${ }^{2}$

In this paper, we take the economic approach to conflict seriously, and apply it to Hindu-Muslim conflict. We construct a simple theory that allows us to link observable economic variables to conflict outcomes. We use the theory to interpret new evidence on the relationship between income and violence in India. In the model (see Section 3), there are two groups: Hindus and Muslims. Depending on the circumstances, members of either group can be aggressors or victims in an inter-religious conflictual encounter. We view such violence as decentralized, though it may place against a backdrop of religious antagonism and orchestrated support from group leaders.

Consider encounters across members of different religious groups: an accident, an assault or confrontation, an isolated murder or rape. When religion is involved, if only by chance, such encounters could boil over into a larger conflict or riot. A potential aggressor involved in the confrontation must decide whether to take advantage of the situation and frame it as a religious conflict, in which members of the other religion can be targeted. The act itself may be motivated by the prospect of economic gain (via direct appropriation or economic exclusion of the victim) or it may be the expression of animosity and resentment, as long as that resentment is sensitive to the economic situations of aggressor and victim.

At the same time, a potential victim can try to defend himself. We consider two technologies of protection. One is "human": the recruitment of community members to safeguard against the possibility of attack. The other is "physical": the use of barricades and gated communities, or the acquisition of weapons. We allow for both avenues, but recognize that their relative use will depend on the economic status of the potential victim.

Our main result (Proposition 1) states that if a group is relatively poor to begin with, an increase in the average incomes of the group - controlling for changes in inequality - must raise violence perpetrated against that group. In contrast, the effect on violence perpetrated by that group on members of the other group is generally negative. ${ }^{3}$

\footnotetext{
${ }^{2}$ Indeed, as Esteban and Ray (2008) and Ray (2009) have argued, there may be good economic reasons for conflict to be salient along noneconomic ("ethnic") lines, rather than along the classical lines of class conflict long emphasized by Marxist scholars.

${ }^{3}$ These nuanced connections between economic growth and conflict suggest that the overall relationship between the two could be non-monotonic. Dube and Vargas (2013) make a parallel observation in the context of resource shocks and violence in Colombia.
} 
We use a unique dataset on Hindu-Muslim violence between 1950 and 1995, compiled by Ashutosh Varshney and Steve Wilkinson, and extended by us to 2000. It summarizes reports from The Times of India on Hindu-Muslim conflicts in India in the second half of the twentieth century. We use counts of the number of people killed, or injured, or the number of riot outbreaks.

We match the data to the large scale household surveys that are conducted quinquennially as part of the National Sample Surveys (NSS). We use data from three consecutive "thick rounds": the 38th in 1983, the 43rd in 1987-88 and the 50th in 1993-94. We compute average per capita monthly expenditures in each round for Hindu and Muslim households in 55 regions, ${ }^{4}$ and so work with a three-period panel.

In several different panel specifications with different sets of controls, Hindu per-capita expenditures have a negative effect on conflict, while the coefficient on Muslim per-capita expenditures is significant and positive. The coefficients are also large. Depending on the exact specification (see Table 3 for baseline results), a $1 \%$ increase in Hindu per-capita expenditure is predicted to decrease casualties by anywhere between 3-7\%, while the same increase in Muslim per-capita expenditure increases casualties by 3-5\%. We conclude that an increase in Hindu prosperity is negatively associated with greater religious fatalities in the near future, while the opposite is true of Muslim prosperity.

The paper subjects these findings to a number of different robustness checks. In all these exercises, the effect of Muslim expenditures remains strong and significant. By and large, the same is true of Hindu expenditure, though in some specifications significance is lost. While the reader is invited to study these robustness exercises in detail, it is worth mentioning here that we find no similar effect of religious group expenditures on social unrest more generally; see Section 5.2. The effect we uncover appears to hold only for instances of Hindu-Muslim conflict.

We interpret our results in light of the model in Section 3. Such an interpretation suggests that Hindu groups have largely been the aggressors in Hindu-Muslim violence in India, or at least in Hindu-Muslim violence driven by instrumental, specifically economic considerations. ${ }^{5}$ Section 2 provides historical context for the model, including references to case studies in which attacks on the Muslim community can be traced to various forms of Muslim economic empowerment.

We emphasize that the above interpretation follows jointly from the theory and the data, and alternative interpretations are possible. Section 5 discusses other explanations with possibly different implications, such as the funding of violence.

The literature on ethnic violence is vast and we do not pretend to review it here: the treatise by Horowitz (2000) is an excellent entry point. It is probably fair to say that the economics of violence have not been given center-stage in most of these writings, the focus being more on other correlates of conflict, such as politics, historical antagonisms, or the presence of ethnic divisions. ${ }^{6}$

At the broad level of cross-country correlates, there is some evidence that negative shocks to per-capita income are conflictual (Collier and Hoeffler 1998, Fearon and Laitin 2003, Miguel,

\footnotetext{
${ }^{4} \mathrm{NSS}$ does not collect data on incomes.

${ }^{5}$ Our findings do not speak to baseline levels of violence, but to the sensitivity of conflict to economic change. However, the model in the Online Appendix shows that the two are related in some circumstances.

${ }^{6}$ See, e.g., Collier and Hoeffler (1998), Fearon and Laitin (2003), Montalvo and Reynal-Querol (2005), and Esteban, Mayoral and Ray (2012).
} 
Satyanath and Sergenti 2004). But in specific cases, economic shocks can have complex effects, as Dube and Vargas (2013) observe in their study of resource shocks and violence in Colombia. ${ }^{7}$ Furthermore, there is little evidence for the argument that the relative deprivation of a group (or economic inequality more generally), is conflictual; see, for instance, Midlarksy (1988) or Lichbach (1989). This ambiguity shows up not just at the cross-country level, but also in specific studies such as those by Spilerman (1970, 1971, 1976), Wilson (1978) and Olzak and Shanahan (1996) on race riots in the urban United States.

One reason for the lack of a connection is that cross-group inequality is correlated with increased segregation of the groups. They interact little and so the frictions are low: as in a caste-based or feudal society, each group knows its place. But as the fortunes of the deprived group improve, the previously advantaged groups may feel threatened, and react with violence. In the words of Olzak and Shanahan (1996), "[W] hen groups come to occupy the same niche, the historically more powerful or advantaged group attempts to exclude competitors. When the less powerful resist these attempts, racial conflict and violence ensues." ${ }^{8}$ This viewpoint has two implications: first, that economic progress can be conflictual; and second, that changes in inequality have ambiguous effects on violence. By linking group incomes to violence and showing that the incomes of antagonistic groups can have opposing effects on the conflict between them, our paper builds upon and contributes to this point of view.

\section{BACKGROUND ON Hindu-MusLim ViolenCE IN INDiA}

As already noted, Hindu-Muslim violence in India extends back to the pre-Partition era. It reached a peak during Partition, and then settled down to sporadic episodes with regular frequency, all the way up to the present day. Many thousands have died from it, not counting the loss of livelihoods or property. There is reason to believe that economic factors play a role in this violence, just as they do in religious or ethnic violence elsewhere. ${ }^{9}$

For instance, Upadhyaya (1992) documents the targeting of Muslim sari dealers in the 1991 Varanasi riots. They were clearly viewed as business rivals. A similar targeting of Muslim cloth manufacturers is seen in the case of the 1984 Bhiwandi riots; see Rajgopal (1987) and Khan (1992):

"[T] he 1984 riots were largely the outcome of business rivalry, though the immediate provocation was provided by the Shivaji Jayanthi procession. The well-entrenched and the newly emerging traders came to perceive competition between them in trade along religious lines. When the competition happens to be between merchants belonging to two religious groups, communal motives are imputed for the success or the failure of the different groups." (Rajgopal, 1987)

Of Meerut, where Muslim powerloom owners had started to diversify economic activity from cloth weaving and printing into other sectors, such as transport and auto-repair, Engineer (1987) writes:

\footnotetext{
${ }^{7}$ Bazzi and Blattman (2013) make a similar point using commodity price shocks.

${ }^{8}$ See also the "split labor" market theory of Bonacich (1972), which argues that labor from clearly demarcated groups of weaker economic strength, such as immigrants, are often used to wear down organized labor, leading to inter-group violence.

${ }^{9}$ See, for instance, Bohr and Crisp (1996) on Kyrgystan, André and Platteau (1998) on Rwanda, Horowitz (2001) on the Ivory Coast and other regions, or Mamdani (2010) on Darfur.
} 
"If [religious zeal] is coupled with economic prosperity, as has happened in Meerut, it has a multiplying effect on the Hindu psyche. The ferocity with which business establishments have been destroyed in Meerut bears testimony to this observation. Entire rows of shops belonging to Muslims ... were reduced to ashes."

Economic targeting during conflict is not confined to eliminating rival businesses or workers. It can consist in direct attacks on entire localities, so as to drive out an ethnic group and affect either housing prices or the opportunity to buy and build. In their analysis of the 2002 Gujarat conflict, Field, Levinson, Pande and Visaria (2008) study locations in which valuable housing was retained by mill workers in residential colonies when the textile mills shut down:

"Once the mills closed, preferential treatment of these lands under the Bombay Rent Control Act implied that residents were granted stronger than average tenancy rights. Since tenancy rights are not transferable on formal real estate markets, mounting tensions between Hindus and Muslims in Gujarat led to a territory war rather than segregation in these locations. As tension mounted, acts of violence and intimidation were used to push out residents belonging to the religious minority group."

This is only one of several studies in which housing is implicated as a factor influencing violence. For instance, Das's (2000) report on the Hindu-Muslim riots in Calcutta in 1992 observes that

“[I]t appears that that 'promoters' played a crucial role in inflaming the riot whose victims ... were slum-dwellers. Their obvious aim was to clear the bustees [or slums] for construction projects... The expectation was that once such people could be forced to abandon their establishments the realtors would have 'an easy way to rake in the fast buck'... What actually took place in 1992 was a land-grabbing riot under a communal garb."

For more on direct economic targeting in Hindu-Muslim violence, see Bagchi (1990), Khan (1992), and the discussion in Wilkinson (2004, Ch. 2).

It seems reasonably clear that in most of these accounts, Muslims suffer a share of the losses that is entirely out of proportion to their population representation (though there are instances running the other way, as in the certain parts of Calcutta during the 1992 riots, such as Metiabruz). That isn't particularly surprising as Muslim populations are generally minorities, and implicit political or police support for Hindu rioters has often been alleged. Drawing on the 9th and 10th Annual Reports of the Minorities' Commission, Wilkinson (2004, p. 30) observes that

"Muslims suffer disproportionately as a result of Hindu-Muslim riots. Hard numbers are difficult to obtain, but of 526 Hindu-Muslim incidents that occurred from 1985 to 1987 in 10 major states, Muslims (12\% of the population) accounted for $60 \%$ of the 443 deaths, $45 \%$ of the 2,667 injuries, and $73 \%$ of the property damage. Given that Muslims are, as a community, much poorer than Hindus the relative effect of communal riots on Muslims economic life is even greater than these percentages suggest... The fact that Muslims suffer disproportionate losses in riots and that Muslim businessmen are more often the victims of looting has convinced many scholars and activists that riots are nothing more than a particularly brutal method of protecting Hindu merchants market share."

Yet writers such as Wilkinson and Horowitz only flirt with the economic argument. While open to the possibility that economic causes may be afoot, their point is that it is one thing to state that 
conflict has a strong economic component, and another to say that economic changes precipitate conflict. So, for instance, Wilkinson (2004, p.30-31) asserts:

"Despite the disparate impact of riots on Hindus and Muslims, however, little hard evidence suggests that Hindu merchants and financial interests are fomenting anti-Muslim riots for economic gain... The fact that economically motivated violence against Muslims occurs after a riot breaks out does not necessarily prove that this is why the violence broke out in the first place."

This echoes the earlier cautionary note sounded in Horowitz (2001, p. 211):

"It is difficult to know how seriously to take commercial competition as a force in targeting choices. In some north Indian cities serious competition has subsisted without any violent episodes. The role that commercial competition is said to play is said to be a covert, behind-the-scenes role, which makes proof or disproof very difficult."

In what follows, we take the economic argument a step further.

\section{THEORY}

3.1. A Model. There are two groups. Members of one group can attack those of the other, possibly by exploiting a past confrontation or violent incident with a possible religious interpretation. The individuals involved - in their role as aggressors — decide whether or not to take matters further by "communalizing" the incident. ${ }^{10}$ At the same time, members of either group — in their role as potential victims — seek security against the possibility of such attacks.

Formally, Nature moves first and generates aggressor-victim pairs belonging to two different religious groups. Each aggressor observes the victim's income or wealth. The victim does not observe aggressor income; this captures the idea that a potential victim makes decisions about protection before an attack occurs. One way to interpret our empirical findings is that it throws some light on the probability that Nature chooses aggressors from one group rather than the other. In short, both groups will have aggressors and victims, the question is one of the relative proportions of each.

A potential victim is characterized by his income or wealth, which we denote by $y$. Let $\alpha$ be the perceived probability of this person being attacked. A victim can seek protection against attack; think of this as "defense" $d$. While not directly affecting $\alpha$ itself (though in equilibrium $\alpha$ will be endogenous), an individual's investment in defense lowers the probability that the attack will be effective. Write this probability as $p=p(d)$, with $p$ continuous and decreasing in $d$. While we regard $d$ somewhat abstractly here, it has several interpretations to which we return below. For now, we simply view a potential victim with income $y$ as picking $d$ to maximize

$$
(1-\alpha) y+\alpha\{p(d)(1-\mu) y+[1-p(d)](1-\beta) y\}-c(d)
$$

where $c(d)$ is the direct or opportunity cost of defense, assumed continuous and increasing in $d, \mu$ is the fraction of gross income lost by the victim in the event of successful attack, and $\beta$ (presumably smaller than $\mu$ ) is the fraction lost in case an attack occurs and turns out to be unsuccessful, where

\footnotetext{
${ }^{10}$ Of the Moradabad riots in 1980 , Rajagopal (1987, p. 75$)$ observes that " $[\mathrm{t}]$ he incident was sparked off by the entry of a pig towards the Namazis (Muslims offering prayers)...." A more common list (p. 87) includes "encroachment on places of worship", "music before mosques", "teasing of girls belonging to the other community", and "provocative articles in magazines."
} 


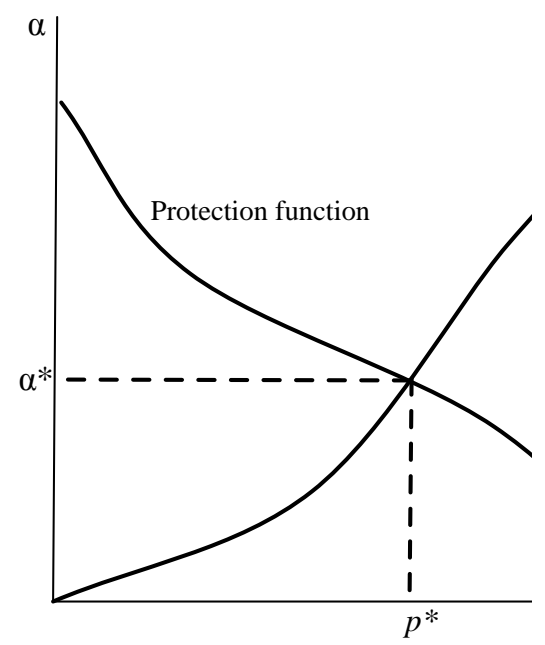

(a) Equilibrium

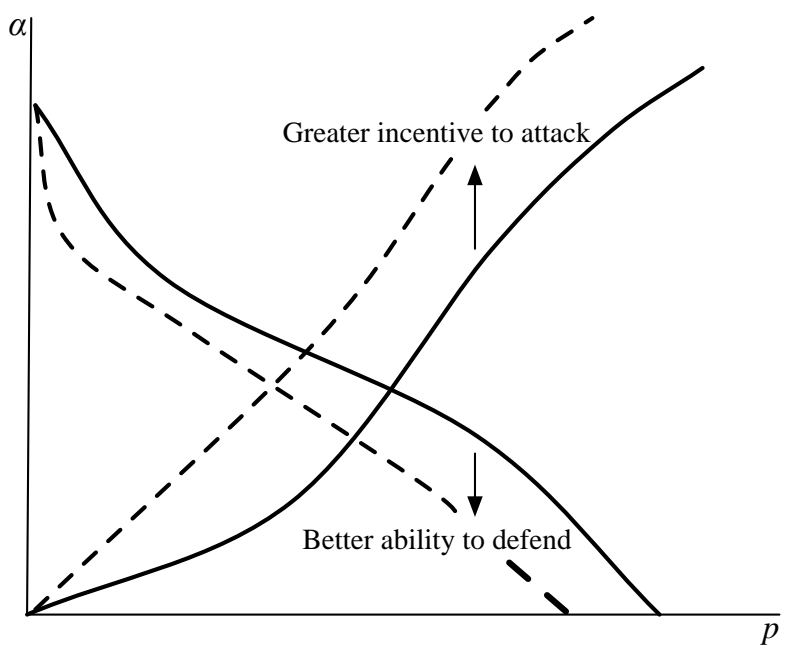

(b) Cross-Section

Figure 1. EQuilibrium. For a given victim, Panel A shows overall probability of attack $\alpha$ as a function of perceived probability of success $p$ (the attack function), and the probability of success $p$ given optimal defense as a function of the likelihood $\alpha$ of being attacked (the protection function). Panel B shows the effect of an increase in victim income on these two functions.

the word "successful" is used from the aggressor's point of view. ${ }^{11}$ This specification incorporates the fact that an attack, successful or not, may still be costly to the victim: $0 \leq \beta<\mu \leq 1$.

This problem is equivalent to the one of choosing $d$ to minimize

$$
\alpha(\mu-\beta) p(d)+[c(d) / y],
$$

where the first term details the extra loss that will accrue from a successful attack, and the second term is the cost of lowering the success probability. Under our assumptions, there is always a solution to the maximization problem. As we track the choices of $d$ (and so $p=p(d)$ ) over different values of $\alpha$, we obtain a best response mapping in $(\alpha, p)$ space, which we call the protection function.

The second best response mapping yields the probability of attack as a function of the perceived probability of success $p$. Call this the attack function. Suppose that a potential aggressor with income $z$ must decide whether or not to participate in violence against an individual with income $y$. Participation involves an opportunity cost, incurred in the fraction of time $t$ spent on conflict. That time could have been spent in productive work. The income loss is therefore $t z$. (We extend this setting to include the expenditure of financial resources in Section 5.3; see also the online Appendix.) The gain could be economic or psychic but, as discussed above, it is positively related to the victim's income $y$. Denote the gain by $\lambda y$. Then an attack will be launched if

$$
(1-p)[1-t] z+p([1-t] z+\lambda y)>z .
$$

Rearranging, we may rewrite this condition as

\footnotetext{
${ }^{11}$ One could just easily write this out in a more sequenced way. For instance, there could be some explicit prior stage at which defense resources are chosen, followed by a second stage in which attacks possibly happen. Our results are also robust to the use of a constant-elasticity utility function defined on net income. The Online Appendix, which the reader is encouraged to read, contains a precise formulation of these and other issues.
} 


$$
z<(\lambda p / t) y
$$

The value $(\lambda p / t)$ establishes a threshold ratio of attacker to victim income below which the attacker will willingly engage in conflict. It is intuitive that a higher probability of success $p$ makes it more attractive to attack, and that an increase in the opportunity cost $t$ makes it less attractive.

It follows that a potential victim with income $y$ faces a likelihood $\alpha$ of being attacked, given by

$$
\alpha=\pi A(\lambda p / t) y
$$

where $\pi$ is the probability of a cross-religious encounter, $p$ is the perceived probability of success, and $A$ is the cumulative distribution function of aggressor incomes, which we assume to be continuous and strictly increasing everywhere. ${ }^{12}$

3.2. Equilibrium. We may now formalize an equilibrium notion for conflict. This is a collection of attack and success probabilities, $\alpha^{*}(y)$ and $p^{*}(y)$, one such pair for every victim income $y$, such that $\alpha^{*}$ is determined by the optimal decisions of the population of potential attackers, given $p^{*}$, while $p^{*}$ is determined by the optimal decisions of potential victims, given $\alpha^{*}$. A simple single-crossing argument, which we record in the Appendix, assures us that the protection function is decreasing, while the attack function is increasing. Their unique intersection determines the equilibrium for every $y$ :

OBSERVATION 1. For every $y$, the protection function generates success probabilities $p$ that weakly decrease in $\alpha$, while the attack function generates attack probabilities $\alpha$ that strictly increase in $p$.

There is a unique equilibrium.

The Appendix contains a proof. Panel A of Figure 1 summarizes an equilibrium for a given victim income. The upward-sloping line is the attack function that generates $\alpha$ as a function of $p$. The downward-sloping line is the protection function. Either function may have jumps, but we can use indifferences (and the assumption of a large population of potential attackers) to fill in these jumps so that the resulting graph is closed. These jumps will actually arise in our later specification of two kinds of protection technologies. The two lines intersect once, telling us there is a unique second-stage equilibrium, as in Observation 1.

In what follows, we are interested in conflict outcomes; specifically, whether or not they are "successful" from the point of view of the aggressor. With a large population of potential attackers, this is equivalent to studying the overall probability of attack.

3.3. The Two Faces of Economic Fortune. This model, elementary though it may be, can be used to address a variety of different questions. In the present exercise, we focus on the effects of group income changes on the likelihood of conflict, which is the value of $\alpha$ averaged over all potential victim incomes.

\footnotetext{
${ }^{12}$ Note that in deriving the attack function, we've used the exogenous income $y$ of the potential victim. In actuality, $y$ may be depleted by expenditures on defense, and it may be augmented by the economic gains of the victim in his role (in other contexts) as aggressor. Similarly, we've used the exogenous income $z$ of the aggressor, and haven't adjusted it for his attack or defense activities elsewhere. The Online Appendix builds a formal model based on this simplification.
} 


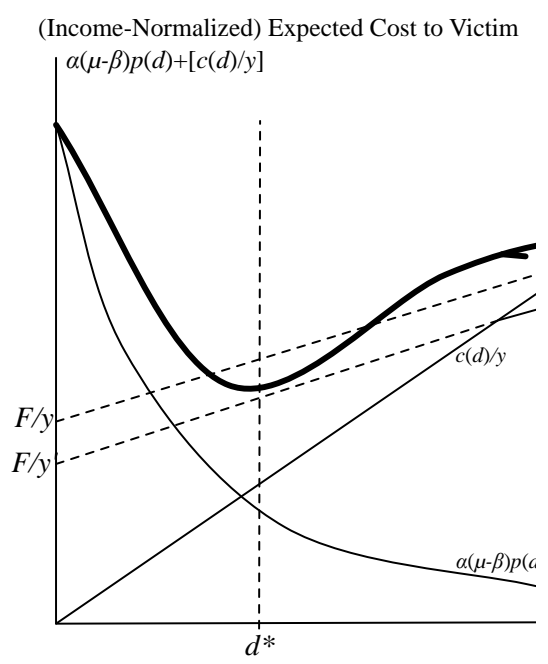

(a) The Defense Respol

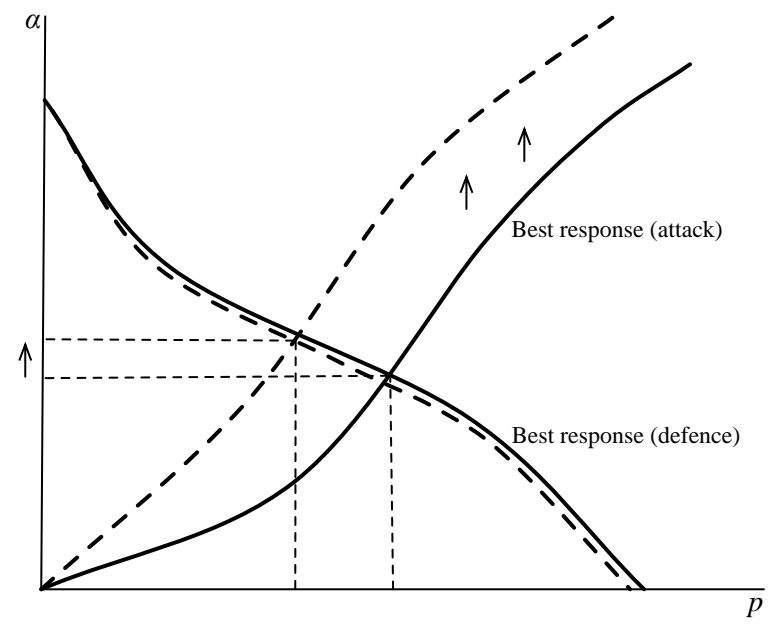

(b) Equilibrium

Figure 2. A Change in Group Fortunes: Low Income. In Panel A, a victim's optimal choice of defence remains unchanged, as cost and benefit move together. In Panel B, this leads to a negligible shift in the protection function and a sizable change in the attack function, so that the probability of attack climbs.

First traverse a cross-section of victim incomes. Imagine drawing a variety of attack and protection functions for different values of the income of a potential victim. It is obvious that the net effect of such changes on $\alpha$ will be ambiguous. Richer victims are a more attractive target for attack, but on the other hand they invest more on protection. The net impact of victim wealth on the probability of attack can, therefore, go in either direction. Panel B of Figure 1 summarizes this situation.

However, the effect of an across-the-board change in group incomes is different. To understand this, one must study the technology of protection or defense, because the cost of deploying that technology will vary with group incomes. Think of two components to protection. The first component is human: protection provided by other individuals in the same community. This is ensured, first and foremost, by living in that community, or at least within easy reach of community members. ${ }^{13}$ Yet that choice cannot but come at a cost. The principal component of that cost lies in the implicit contract of protection. It may well be the case that compatriots would spontaneously defend a potential victim, but such defense is rarely free: by and large, equal contributions will have to be made to the community or obligations incurred, such as the reciprocal protection of others. But the cost of that reciprocity must be commensurate with the opportunity cost of providing protection services, which is related to the average of group incomes to which our victim belongs. We therefore expect that the cost of "human protection" will be proportional to group incomes.

The second component of protection largely involves the use of physical capital: the purchase of security through the use of high walls, barricades, and firearms. This sort of protection is generally extremely effective in reducing attack, but involves high fixed costs: the purchase of weaponry (and the hiring of security guards to use them), the erection of high walls around one's property, and so on. Unlike human protection, the cost of this component will be less-than-proportionately

\footnotetext{
${ }^{13}$ In the Hindu-Muslim case, see, for instance, Mahadevia (2002) and Chandoke (2009) on the high residential segregation in Ahmedabad. Over 70\% of the Ahmedabad sample studied in Field, Levinson, Pande and Visaria (2008) lived in segregated communities.
} 
related to group incomes, and to the extent that it is fully reliant on physical capital, not related at all. Specifically, we suppose that

$$
c(d)=\min \left\{w d, F^{*}+w^{*} d\right\}
$$

where the first entry represents a protection technology with a dominant human component, and the second a technology with a dominant physical component, with the potential advantage that it has lower variable costs. That is, $w>w^{*} \geq 0$. The important assumption that we make is that the variable costs $w$ are fully human (and borne by individuals in the same group), and therefore proportional to average group incomes.

Proposition 1. Assume that $w$ is proportional to average group incomes. Then:

(a) There exists a threshold income $y^{*}$ such that an equiproportionate increase in group incomes that keeps all incomes below $y^{*}$ increases the probability of attack on group members.

(b) An equiproportionate increase in the incomes of a group unambiguously lowers attacks instigated by members of that group.

Parts (a) and (b) represent the two faces of economic fortune. An improvement in the fortunes of a potential victim make him a more lucrative target, so that violence increases. An improvement in the fortunes of a potential aggressor increases the opportunity cost of engaging in conflict, so that violence decreases. The sign of the correlation between group incomes and subsequent violence tells us something about whether that group contains a preponderance of victims or attackers.

To understand how the proposition works, consult Figure 2. Consider a potential victim, whose income increases (in the same proportion as his group's) from $y$ to $y^{\prime}$. The thin downwardsloping line in Panel (a) is the function $\alpha(\mu-\beta) p(d)$, which is the expected loss per unit of victim income in the event of an attack. The piecewise linear segment in that panel is the function $c(d)=\min \left\{w d, F^{*}+w^{*} d\right\}$, deflated by victim income $y$. The thick nonlinear curve is the sum of these two functions, which our individual seeks to minimize via choice of $d$.

Given that our individual's income shift mirrors the overall group shift, and that $w / y$ is unaffected by group income, there is no change in the sum of the two curves up to some threshold, after which it moves down. This happens because fixed costs are effectively reduced when deflated by rising income, and the ratio of subsequent variable cost $w^{*}$ to income could be reduced as well. The sum of the two functions therefore moves as shown in Panel A. However, in this panel, the individual in question has low income, and the capital-intensive technology is not attractive even after the effective fixed cost shifts down. A change in group incomes then has no effect on the optimally chosen defense expenditure of that individual.

Moving over to Panel B with this information, we see that when incomes are low, the variable cost of defense expenditure moves in tandem with incomes, and the protection function does not shift with a change in group incomes. At the same time, each individual in the group becomes a more attractive target: the attack function shifts upward, and it becomes more profitable to launch an attack for any fixed value of $p$. The net effect is an increase in equilibrium attack probability.

It is easy enough to define a threshold $y^{*}$ which is sufficient to generate all the effects above. Note that the highest probability of an attack is bounded above by $\pi$, the probability of a cross-religious confrontation. If, at this level, it is optimal for an individual to choose the "human protection" 


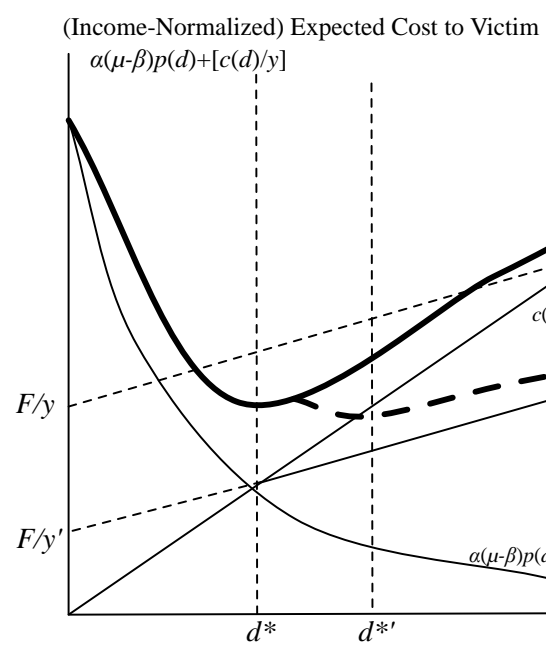

(a) The Defense Respor

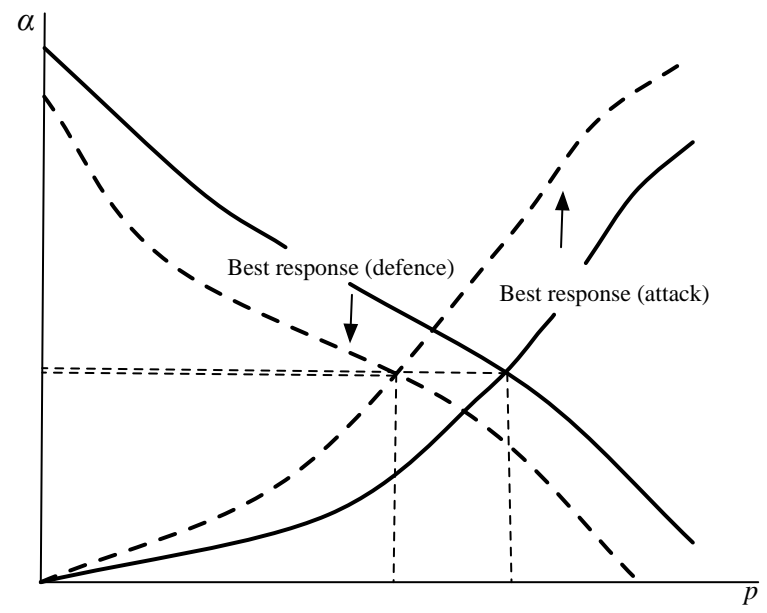

(b) Equilibrium

Figure 3. A Change in Group Fortunes: High Income. In Panel A, a victim's optimal choice of defence shifts away from human mode. In Panel B, this leads to a sizable shift in both attack and protection function, so that the probability of attack changes in ambiguous fashion.

technology, then by the first part of Observation 1, it is optimal to do so for all lower levels. It is straightforward to see that such a threshold must exist. ${ }^{14}$

For individuals with incomes that exceed this threshold, the capital-intensive technology may be attractive. If it is attractive both before and after the change in group incomes, then the effect on $d$ will depend on the ratio of $w^{*}$ to $y$. If $w^{*}$ is a fully human cost and involves the use of fellow group members, it will again be proportional to group means, and previous arguments apply. The ambiguity arises from individuals whose incomes cross the threshold. Figure 3 shows what happens with incomes that rely on the human technology before the change, but move into the fixed-cost technology after the change. Panel A shows that it is now possible for there to be a sharp upward jump in defense expenditures. ${ }^{15}$ The protection function shifts downwards, as in Panel B, while the attack function (as before) shifts upwards. The net effect will depend on the relative strengths of these two shifts, and it is ambiguous.

The effect on overall attacks will depend on the proportion of individuals who fall below the threshold for which the capital-intensive technology is never used. The more individuals there are in this category, the more likely it is that economic improvement will generate greater violence directed against the group in question.

In contrast, consider a potential aggressor, whose income increases from $z$ to $z^{\prime}$, and look at the attacks perpetrated by him. Given the assumptions of our model, there is no ambiguity here at all: the opportunity cost of engaging in violence goes up, and aggression must decline. Formally, the inequality (1) is less likely to hold for any aggressor-victim pair, and so - all other things being equal - the probability of attack, as given by (2), must come down.

\footnotetext{
${ }^{14}$ Recall that $w$ is linear in average incomes and is therefore bounded above by a fraction of $Y$, if all incomes in society are smaller than $Y$. Moving $Y$ down lowers $w$ and must create a cross-over to the human protection technology at some positive level even if $w^{*}=0$. This level is sufficient for our needs (it may be far from necessary).

${ }^{15}$ By mixing across individuals who are indifferent between making this change, we can always make sure that the graph of the protection function is continuous, so that an equilibrium exists.
} 


\section{EMPIRICAL ANALYSIS}

4.1. Data. Systematic statistical information on outbreaks of religious violence in India is relatively hard to come by, and our choice of time period is constrained by the available overlap of conflict data and economic information. On conflict, we use a dataset compiled by Steven Wilkinson and Ashutosh Varshney. (See, in particular, the recent use of this data in Wilkinson, 2004.) It summarizes reports from The Times of India, a leading national newspaper, on Hindu-Muslim conflicts in India in the second half of the twentieth century. This dataset has information on deaths, injuries, and arrests. It does not provide hard information on which side initiated the violence, for in most cases that issue would necessarily be mired in subjectivity. For every report of Hindu-Muslim violence, the dataset provides the date of incidence of the riot, the name of the city/town/village, the district and state, its duration, the number of people killed, injured and arrested and the reported proximate cause of the riot.

The following summary provides some sense of the pervasiveness and intensity of Hindu-Muslim riots in post-Independence India. Between 1950 and 1995, close to 1,200 separate riot episodes were reported, with over 7,000 individuals killed. Between 1950 and 1981, the average number of Hindu-Muslim riots in India was 16 per year. This same number for the period between 1982 and 1995 happens to exceed 48 . Over these 14 years, a total of 674 riots were reported with close to 5000 deaths. Therefore, over half the reported riots between 1950 and 1995 (and around 2/3 of total deaths) occurred during a period that was less than one-third as long as the total period for which we have data. In other words, religious conflict appears to have sharpened significantly as we move from 1950-81 to 1982-95.

We utilize the Varshney-Wilkinson data from 1979 to 1995. Furthermore, we have extended this conflict dataset by a period of five years, i.e., from 1996 to $2000 .^{16}$ The main reason for limiting ourselves to this time period is the non-availability of reliable data on economic conditions (by religious group) for earlier years. At the same time, the observations made above highlight the importance of religious violence in the 1980s and 90s.

We use three different count measures from the dataset: the number of people killed or injured ("casualties"), the number of people killed or the number of riot outbreaks over the period. In all cases, we take aggregates over a five year period in each location.

As for economic data, large scale household surveys are conducted quinquennially in India as part of the National Sample Surveys (NSS). The survey rounds cover the entire nation and capture monthly expenditure incurred by sample households for domestic consumption. ${ }^{17}$

\footnotetext{
${ }^{16}$ In conducting this exercise, we have adhered to the same data collection protocol as followed in the construction of the original dataset. To ensure consistency, we have kept the source of these data (from 1996-2000) the same as that used by Varshney and Wilkinson; namely, the reports from The Times of India.

${ }^{17}$ Unfortunately, a well-known problem in the case of the NSS is that we do not have income data on a nationwide scale, and expenditure is the closest we can get.
} 
The earliest "thick" round that provides spatially disaggregated economic information by religion is the 38th round (1983). ${ }^{18}$ We use three such "thick" rounds: the 38th (1983), the 43rd (19871988) and the 50th (1993-94). For all of these rounds there is information on the religious affiliation of the household, or more precisely, the head of the household. This enables us to compute the per-capita monthly expenditure of Hindu and Muslim households.

However, we are further restricted by the relative lack of spatial disaggregation in the 38th and the 50th rounds, which do not permit identification of the surveyed households all the way down to the district level. To use all three rounds (and thereby exploit the panel structure), we must aggregate the Varshney-Wilkinson dataset up to the regional level in India, "regions" being formally defined as areas that are midway between the state and the district. We do so for 55 such regions, which together span 14 major Indian states and account for more than $90 \%$ of the Indian population. ${ }^{19}$

We also employ a number of controls: population by region, religious polarization across Hindus and Muslims, the literacy rate, the completion rate for primary education, urbanization, calculated as the percentage of urban households in the region, the share of regional Lok Sabha seats won by the Bharatiya Janata party (BJP), and Gini coefficients as controls for expenditure inequality among Hindu and Muslims.

4.2. Preliminary Observations. Although incidents of Hindu-Muslim violence have been reported all over India, there are some regions that appear to be particularly prone to such outbreaks. The "conflict" columns of Table 1 tell us that the states of Gujarat and Maharashtra have witnessed major outbreaks whereas states like Punjab, Haryana and Orissa have experienced very few such incidents.

The "expenditure" columns of Table 2 provide a quick guide to Hindu-Muslim expenditure disparities in different states of India. The table provides state averages as well within-state regional variations. On the whole, Hindu households have a higher average monthly per-capita expenditure than their Muslim counterparts. But Table 2 also reveals the large variation in Hindu-Muslim expenditure ratios across the regions of India. This ratio was as low as 0.36 in a region in Orissa in 1983 and as high as 1.93 in a region in Haryana in 1993-94.

Around the time period considered in our study, several changes impacted differentially on Hindus and Muslims, thereby allowing for a degree of independent movement in their incomes. Here are two examples. First, positive shocks to oil prices, starting with the concerted efforts of OPEC in the 1970s, resulted in a huge increase in the demand for labor from the Gulf countries. That resulted in a substantial emigration of workers from India to the Gulf over the next few decades. In particular, members of the Muslim communities in Kerala, Tamil Nadu and Andhra Pradesh

\footnotetext{
${ }^{18}$ NSS surveys which occur annually utilize smaller samples and hence are referred to as "thin" rounds. However, the rounds performed quinquennially draw upon larger samples (about 120,000 households per survey); hence the term "thick".

${ }^{19}$ We leave out border states with their own specific sets of problems: Jammu \& Kashmir and Himachal Pradesh in the north, and the north-eastern states of Assam, Arunachal Pradesh, Manipur, Meghalaya, Nagaland, Sikkim and Tripura. There are two specific issues with these areas: (i) NSS does not survey all regions within these states (owing to hilly terrain, safety issues, national security reasons due to border skirmishes, etc.), and (ii) for the border states it is sometimes difficult to tell whether a reported riot is indeed civilian in nature or due to the Army clashing with extremist groups. In addition, the north-eastern states (which happen to be sparsely populated) have an insignificant Muslim population: they are primarily Hindus, Christians, Buddhists and Scheduled Tribes. So even in the violence dataset there are almost no reports of riots there.
} 


\begin{tabular}{lrrrrrrrrr}
\hline State & \multicolumn{3}{c}{$1984-88$} & \multicolumn{4}{c}{$1989-93$} & \multicolumn{3}{c}{$1994-98$} \\
& Casualties & Killed & Outbreak & Casualties & Killed & Outbreak & Casualties & Killed & Outbreak \\
\hline Andhra Pradesh & 320 & 48 & 14 & 226 & 165 & 11 & 141 & 8 & 2 \\
Bihar & 62 & 18 & 4 & 647 & 485 & 29 & 187 & 42 & 6 \\
Gujarat & 1932 & 329 & 97 & 1928 & 557 & 75 & 639 & 2 & 3 \\
Haryana & 0 & 0 & 0 & 6 & 4 & 2 & 0 & 0 & 0 \\
Karnataka & 300 & 38 & 19 & 430 & 82 & 32 & 235 & 39 & 7 \\
Kerala & 17 & 0 & 2 & 42 & 5 & 3 & 0 & 0 & 0 \\
Madhya Pradesh & 139 & 17 & 8 & 794 & 174 & 12 & 22 & 2 & 1 \\
Maharashtra & 1250 & 333 & 57 & 2545 & 808 & 29 & 238 & 9 & 11 \\
Orissa & 0 & 0 & 0 & 62 & 16 & 6 & 0 & 0 & 0 \\
Punjab & 13 & 1 & 1 & 0 & 0 & 0 & 0 & 0 & 0 \\
Rajasthan & 14 & 0 & 4 & 302 & 75 & 15 & 66 & 6 & 3 \\
Tamil Nadu & 21 & 1 & 1 & 125 & 12 & 5 & 67 & 33 & 5 \\
Uttar Pradesh & 963 & 231 & 38 & 1055 & 547 & 48 & 217 & 50 & 22 \\
West Bengal & 71 & 19 & 7 & 148 & 59 & 12 & 0 & 0 & 0 \\
\hline
\end{tabular}

Table 1. Descriptive Statistics: Conflict. Sources and Notes. Varshney-Wilkinson dataset on religious riots. "Conflict" is measured by aggregates of casualties (killed + injured), killed and outbreaks over a five-year period.

\begin{tabular}{|c|c|c|c|c|c|c|c|c|c|}
\hline \multirow[b]{2}{*}{ State } & \multicolumn{3}{|c|}{1983} & \multicolumn{3}{|c|}{$1987-8$} & \multicolumn{3}{|c|}{ 1993-4 } \\
\hline & H-M exp. ratio & Min & $\operatorname{Max}$ & H-M exp. ratio & Min & Max & H-M exp. ratio & Min & Max \\
\hline Andhra Pradesh & 0.99 & 0.96 & 1.09 & 0.99 & 0.92 & 1.17 & 0.99 & 0.84 & 1.16 \\
\hline Bihar & 0.98 & 0.88 & 1.12 & 1.07 & 1.02 & 1.12 & 1.03 & 0.93 & 1.16 \\
\hline Gujarat & 1.02 & 0.89 & 1.19 & 0.98 & 0.78 & 1.14 & 1.06 & 0.88 & 1.13 \\
\hline Haryana & 1.20 & 1.07 & 1.53 & 0.96 & 0.85 & 1.05 & 1.60 & 1.39 & 1.93 \\
\hline Karnataka & 0.98 & 0.84 & 1.19 & 1.00 & 0.83 & 1.07 & 1.01 & 0.69 & 1.15 \\
\hline Kerala & 1.10 & 1.07 & 1.19 & 1.15 & 1.15 & 1.16 & 1.01 & 0.92 & 1.16 \\
\hline Madhya Pradesh & 0.92 & 0.78 & 1.38 & 0.86 & 0.71 & 1.04 & 0.88 & 0.62 & 1.16 \\
\hline Maharashtra & 1.04 & 0.97 & 1.25 & 1.04 & 0.74 & 1.29 & 1.12 & 0.87 & 1.42 \\
\hline Orissa & 0.69 & 0.36 & 1.04 & 0.85 & 0.58 & 0.93 & 0.96 & 0.73 & 1.13 \\
\hline Punjab & 0.86 & 0.75 & 1.15 & 1.21 & 1.19 & 1.22 & 1.18 & 1.08 & 1.34 \\
\hline Rajasthan & 0.97 & 0.43 & 1.18 & 1.02 & 0.46 & 1.19 & 1.22 & 1.06 & 1.35 \\
\hline Tamil Nadu & 1.06 & 0.82 & 1.44 & 0.88 & 0.80 & 0.94 & 0.98 & 0.85 & 1.05 \\
\hline Uttar Pradesh & 1.12 & 1.01 & 1.23 & 1.11 & 0.95 & 1.54 & 1.08 & 0.93 & 1.31 \\
\hline West Bengal & 1.18 & 1.05 & 1.26 & 1.21 & 1.05 & 1.31 & 1.25 & 1.07 & 1.38 \\
\hline
\end{tabular}

Table 2. Descriptive Statistics: Economic Data. Sources and Notes. National Sample Survey 38th, 43rd and 50th rounds. H-M exp. ratio = Hindu per-capita expenditure/ Muslim per-capita expenditure, average value for the state. The range for the state comes from the constituent regions of the state.

contributed to this steady flow of migrant workers (see, e.g., Azeez and Begum (2009)). In turn, this flow resulted in remittances back to India from the Gulf, some of it resulting in highly visible 


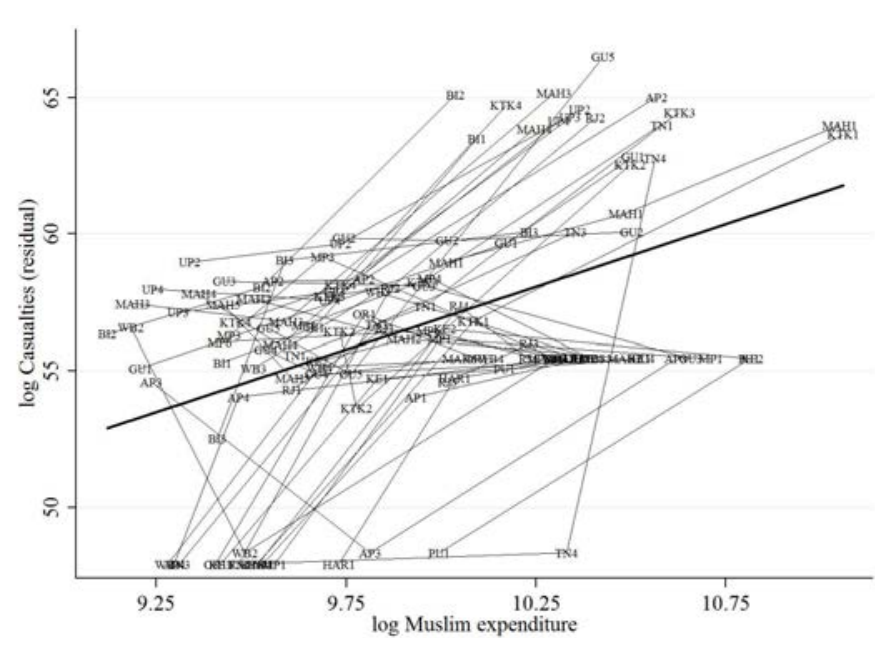

(a) Conflict and Muslim Expenditure

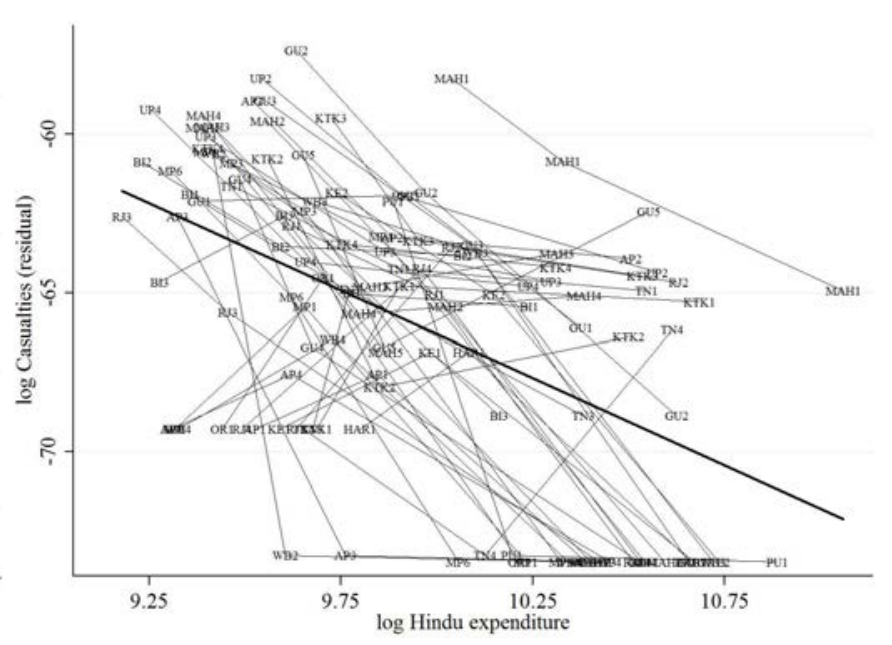

(b) Conflict and Hindu Expenditure

Figure 4. CONFLICT AND PER-CAPITA EXPENDiture. Each panel plots the residual of casualties after region and time effects have been removed, in the 5-year period following expenditures. Each line segment connects three data points for a region.

real estate booms. ${ }^{20}$ Second, the trade liberalization process in India, set in motion in 1991, has led to the continuation and heightening of changes with even earlier origins. In particular, while some sectors made substantial gains from this liberalization process, the unorganized tertiary sector has suffered, certainly in relative and perhaps in absolute terms. After all, this sector has practically no safety nets to cope with the structural changes accompanying globalization. It is well known (see, e.g., Basant (2012)) that Muslims are heavily concentrated in this sector; furthermore, they mostly happen to be poor and self-employed. Therefore, such Muslim households were more at the mercy of the broad, sweeping changes which liberalization brought in its wake.

We combine these economic changes with information on Hindu-Muslim conflict from the VarshneyWilkinson dataset. As a starting observation, Figure 4 considers (the logarithm of) Hindu and Muslim per-capita expenditure by region at each of three rounds of the NSS, and conflict measured by (the logarithm of) total "casualties" — killed plus injured — in the five-year period starting immediately after the rounds. Because regions vary so widely in average conflict levels and because there are nationwide trends over the three periods, we remove region-specific and time-specific effects. With no other controls in place, the figure plots the two sets of residuals.

The remarkable pattern that emerges is one we will repeatedly verify over several robustness checks: conflict appears to react significantly and positively to an increase in Muslim per-capita expenditures, while the opposite reaction occurs to an increase in Hindu per-capita expenditure: conflict declines. Indeed, we display each regional observation as a line segment joining three observations, so the reader can even see the effect "region by region": the line segments are generally upward-sloping in the first panel of the Figure, and downward-sloping in the second. A second objective of our paper is to interpret these two different effects by constructing and applying a simple theory of economic violence.

\footnotetext{
${ }^{20}$ See, for instance, Rajagopal (1987, p. 35): "The boom in the economy of the Arab countries in the Middle East has been a blessing ... the youths and the entrepreneurs among the Muslims have also capitalized on this boom. This accounts for a distinct spurt in the economic affluence of Muslims in certain parts of the country."
} 
4.3. Specification. For the reasons given in the theoretical section of this paper, we are interested in the effect of Hindu and Muslim per-capita expenditures on religious violence. As already described, our dependent variables are different measures (or specifically, counts) of Hindu-Muslim violence. The independent variables and the expected signs on them come from the theory. Recall that in equilibrium, violence is proportional to the total number of attacks, given by

$$
\pi\left[\nu_{1} \int_{y_{2}} F_{1}\left(\lambda_{1} p_{2}\left(y_{2}\right) y_{2} / t_{1}\right) d F_{2}\left(y_{2}\right)+\nu_{2} \int_{y_{1}} F_{2}\left(\lambda_{2} p_{1}\left(y_{1}\right) y_{1} / t_{2}\right) d F_{1}\left(y_{1}\right)\right],
$$

where $\pi$ is the probability of a cross-match and subscript $i$ stands for variables pertaining to group $i$. The first term within the square brackets denotes attacks generated by aggressors in group 1 on victims in group 2, and the second term switches the roles of the two groups. The weights $\nu_{1}$ and $\nu_{2}$ tell us how important each configuration is in generating the overall conflict that we observe.

The cross-match probability $\pi$ will be increasing in both the extent of Hindu-Muslim polarization as well as in overall population. Proposition 1 tells us, additionally, that attack data will depend on average incomes in each group. Taken together, this motivates a Poisson specification in which the parameter depends on all these variables, with possibly additional region- and time-specific variation. This motivates the baseline Poisson specification that we use:

$$
\mathbb{E}\left(\text { Count }_{i, t} \mid \mathbf{X}_{i t}, \gamma_{i}\right)=\gamma_{i} \exp \left(\mathbf{X}_{i t}^{\prime} \beta+\tau_{t}\right)
$$

where we add in region effects $\gamma_{i}$ as well as time effects $\tau_{t}$ in the panel regressions below. Note, the subscript $i$ represents region while $t$ denotes time.

We also use the Negative Binomial and OLS specifications as robustness checks. OLS has the advantage of easier interpretation of the coefficients compared to count models such as the Poisson and Negative Binomial. However, to avoid losing observations in cases where reported conflict is zero, we add a very small number (0.01) to the total count variable, so that the dependent variable for the OLS regressions is actually $\ln ($ count +0.01$)$. So our OLS specification is:

$$
\ln \left(\operatorname{count}_{i t}+0.01\right)=\gamma_{i}+\tau_{t}+\mathbf{X}_{i t}^{\prime} \beta+\text { error }_{i t} .
$$

The most important variables in $\mathbf{X}$ are, of course, Muslim and Hindu per-capita expenditures (our proxies for per-capita income), and in some variants their ratio. Population and some measure of Muslim presence are always included as controls in every specification (despite the region fixed effects, these are important variables that potentially vary with time). Muslim "presence" is measured in two ways: we use either the share of Muslim households in the region, or a measure of Hindu-Muslim polarization along the lines proposed by Esteban and Ray (1994) and Montalvo and Reynal-Querol (2005). ${ }^{21}$ To be sure, in all the regressions we either control for Muslim percentage or religious polarization but never both simultaneously. The correlation between these two variables is very high (about 0.97 ). ${ }^{22}$ We also control for expenditure inequality among Hindu and Muslims, as our predictions pertain to balanced increases in income for either group.

The basic controls are constructed using the data from the NSS rounds. In some specifications, we also use an expanded set of controls, to be described below. In all the specifications, expenditures and population are entered logarithmically, and all other controls are brought in linearly.

\footnotetext{
${ }^{21}$ The degree of religious polarization for a region is defined by $4 \sum s_{j}^{2}\left(1-s_{j}\right)$ for $j=H, M$ where $H$ denote Hindus and $M$ Muslims and $s_{j}$ denotes the population share of $j$ in the region.

${ }^{22}$ In some areas, there are other dominant religious groups (like Sikhs in Punjab), so that Muslim percentage and Hindu-Muslim polarization measure different things. But these cases are exceptions rather than the rule.
} 


\begin{tabular}{|c|c|c|c|c|c|}
\hline & $\begin{array}{c}\text { Poisson } \\
{[\mathbf{1 1}]}\end{array}$ & $\begin{array}{c}\text { Poisson } \\
{[2]}\end{array}$ & $\begin{array}{c}\text { Poisson } \\
\text { [3] }\end{array}$ & $\begin{array}{c}\text { Neg. Binom. } \\
\text { [4] }\end{array}$ & $\begin{array}{l}\text { OLS } \\
{[5]}\end{array}$ \\
\hline Hindu per-capita expenditure & $\begin{array}{r}* * *_{-}-8.325 \\
(0.005)\end{array}$ & $\begin{array}{r}* * *_{-}-7.869 \\
(0.005)\end{array}$ & $\begin{array}{r}* * *-6.824 \\
(0.003)\end{array}$ & $\begin{array}{r}-3.310 \\
(0.131)\end{array}$ & $\begin{array}{r}*_{-} 8.462 \\
(0.085)\end{array}$ \\
\hline Muslim per-capita expenditure & $\begin{array}{r}* * * 5.627 \\
(0.000)\end{array}$ & $\begin{array}{r}* * * 5.103 \\
(0.000)\end{array}$ & $\begin{array}{r}* * * 4.670 \\
(0.001)\end{array}$ & $\begin{array}{r}* * 3.872 \\
(0.023)\end{array}$ & $\begin{array}{r}* * * 9.523 \\
(0.009)\end{array}$ \\
\hline Population & $\begin{array}{l}3.353 \\
(0.554)\end{array}$ & $\begin{array}{l}4.280 \\
(0.468)\end{array}$ & $\begin{array}{l}3.914 \\
(0.496)\end{array}$ & $\begin{array}{l}0.744 \\
(0.132)\end{array}$ & $\begin{array}{r}-1.230 \\
(0.877)\end{array}$ \\
\hline Religious Polarization & $\begin{array}{r}5.103 \\
(0.104)\end{array}$ & $\begin{array}{r}* 5.552 \\
(0.054)\end{array}$ & $\begin{array}{r}* 5.566 \\
(0.056)\end{array}$ & $\begin{array}{r}1.094 \\
(0.715)\end{array}$ & $\begin{array}{r}6.860 \\
(0.408)\end{array}$ \\
\hline Literacy Rate & & $\begin{array}{r}0.021 \\
(0.298)\end{array}$ & $\begin{array}{r}0.023 \\
(0.242)\end{array}$ & $\begin{array}{l}-0.015 \\
(0.525)\end{array}$ & $\begin{array}{r}-0.043 \\
(0.552)\end{array}$ \\
\hline Urbanization Rate & & $\begin{array}{r}-0.020 \\
(0.258)\end{array}$ & $\begin{array}{l}-0.017 \\
(0.354)\end{array}$ & $\begin{array}{r}0.015 \\
(0.405)\end{array}$ & $\begin{array}{r}-0.055 \\
(0.371)\end{array}$ \\
\hline Gini: Hindu per-capita exp. & & & $\begin{array}{l}-5.426 \\
(0.317)\end{array}$ & $\begin{array}{l}4.121 \\
(0.521)\end{array}$ & $\begin{array}{r}-14.473 \\
(0.342)\end{array}$ \\
\hline Gini: Muslim per-capita exp. & & & $\begin{array}{r}3.399 \\
(0.497)\end{array}$ & $\begin{array}{r}-5.952 \\
(0.362)\end{array}$ & $\begin{array}{r}-11.073 \\
(0.451)\end{array}$ \\
\hline $1 \%$ rise in Hindu exp. reduces conflict by & $8.0 \%$ & $7.6 \%$ & $6.5 \%$ & $3.2 \%$ & $8.1 \%$ \\
\hline $1 \%$ rise in Muslim exp. raises conflict by & $5.7 \%$ & $5.2 \%$ & $4.8 \%$ & $3.9 \%$ & $9.9 \%$ \\
\hline Log-Likelihood/Adjusted $R^{2}$ & $-3,468$ & $-3,416$ & $-3,357$ & -302.20 & 0.348 \\
\hline Observations & 129 & 129 & 129 & 129 & 129 \\
\hline
\end{tabular}

Table 3. The Effect of Hindu and Muslim Expenditures on Regional Conflict: FE regressions with Poisson, Negative Binomial and OLS, respectively. Sources and Notes. Varshney-Wilkinson dataset on religious riots, National Sample Survey 38th, 43rd and 50th rounds. "Conflict" is measured by regional aggregates of casualties (killed or injured) over a five-year period starting immediately after the expenditure data. Robust standard errors clustered by region; corresponding $p$-values in parentheses. Time dummies included in all regressions. *significant at $10 \% * *$ significant at $5 \% * * *$ significant at $1 \%$

We look at the effect of these expenditure variables on Hindu-Muslim conflict starting the year right after the corresponding expenditure round. Specifically, expenditures from the 38th round (1983) are matched with conflict during 1984-88, the 43rd round (1987-88) expenditures are matched with conflict during 1989-93 while the 50th round (1993-94) expenditures are matched with conflict during 1994-1998. Lag specifications and issues of endogeneity are discussed in some detail below. All specifications utilize both region and time fixed effects.

4.4. Basic Results. Table 3 contains the main results for our region-based panel specification. We present three different regression models: the first two are count models (Poisson and Negative Binomial, respectively) and the third is OLS.

For each of the three regression models, we display three columns. The first column has minimal controls (only population and a measure of Muslim presence), while the second column controls 
in addition for literacy and urbanization. The third column further includes measures of withinHindu and within-Muslim inequalities. In all panel specifications with or without controls, the coefficient on Muslim expenditures is significant and positive. In contrast, Hindu expenditures exhibit a negative effect on casualties.

The coefficients on both Hindu and Muslim expenditures are also large. A one percent increase in Muslim expenditures is predicted to increase casualties - starting the very next year — by around $5 \%$ in the fixed effects Poisson model. The corresponding estimate for the Negative Binomial model is around 3\%. The same change in Hindu expenditure has corresponding effects ranging from $-7 \%$ in the Poisson specification to $-3 \%$ for the Negative Binomial model. To be sure, a $1 \%$ increase in expenditure may require a bit more than a $1 \%$ increase in underlying incomes, if the consumption function is concave, or if there is smoothing of income shocks via insurance or credit. But there is little doubt that the effect is significant and large, and strongly suggests that an increase in Muslim prosperity is positively associated with greater religious fatalities in the near future, while the opposite is true of a change in Hindu prosperity.

Below, we discuss several variations. Before we do so, we take explicit note of the controls for within-group economic inequality, as measured by the Gini coefficients on Hindu and Muslim expenditures. The controls, introduced in Column 3 of our basic specification, will be used in all the relevant variations below. It is important to maintain these controls as our theoretical predictions regarding income changes and its consequent effect on violence are based on "balanced changes" in group incomes. To be sure, "unbalanced changes", or changes in inequality, can also have their own set of effects (see Esteban and Ray, 2008, 2011, and Huber and Mayoral, 2013), but this is not something we seriously investigate in this paper. In any case, the inclusion or exclusion of inequality controls makes no serious difference to the main results of the paper.

In what follows, we explore the robustness of the basic finding to alternative specifications, and discuss questions of interpretation.

4.5. Variations. The basic results are robust to the many different variations we've tried; we discuss some of them in this section.

4.5.1. Other Dependent Variables. The use of alternative count variables generate similar results. We can move to progressively coarser indicators: the number killed in riots or simply the number of outbreaks. Table 4 records some of these findings. As before, we report results for all three regression models: Poisson, Negative Binomial and OLS. For each of the three models, the first column runs the exercise for all killed, while the second column does so for the number of reported riots. All these variants consistently report that an increase in Muslim per-capita expenditure is positively and substantially correlated with later occurrences of conflict.

4.5.2. Expenditure Ratios. Table 3 has the interesting feature that Muslim and Hindu expenditures have not only the opposite sign, they have roughly the same impact. Indeed, in all our specifications, the two expenditures can be easily replaced by their ratio. As expected, a higher ratio of Muslim to Hindu income, controlling for overall per-capita income, is positively and significantly associated with greater subsequent conflict. See column 1 in Table 5. 


\begin{tabular}{|c|c|c|c|c|c|c|}
\hline & \multicolumn{2}{|c|}{ Poisson } & \multicolumn{2}{|c|}{ Negative Binomial } & \multicolumn{2}{|c|}{ OLS } \\
\hline & $\begin{array}{l}{[1]} \\
\text { Killed }\end{array}$ & $\begin{array}{c}{[2]} \\
\text { Outbreak }\end{array}$ & $\begin{array}{c}{[3]} \\
\text { Killed }\end{array}$ & $\begin{array}{c}{[4]} \\
\text { Outbreak }\end{array}$ & $\begin{array}{c}{[5]} \\
\text { Killed }\end{array}$ & $\begin{array}{c}{[6]} \\
\text { Outbreak }\end{array}$ \\
\hline Hindu per-capita expenditure & -0.073 & -2.122 & -2.249 & $*_{-5.369}$ & -4.267 & $* *_{-} 6.304$ \\
\hline Muslim per-capita expenditure & $\begin{array}{r}(0.976) \\
0.852 \\
(0.636)\end{array}$ & $\begin{array}{r}(0.393) \\
* 2.493 \\
(0.067)\end{array}$ & $\begin{array}{r}(0.293) \\
* * 3.692 \\
(0.030)\end{array}$ & $\begin{array}{r}(0.069) \\
* * 4.158 \\
(0.016)\end{array}$ & $\begin{array}{r}(0.339) \\
* * 6.415 \\
(0.043)\end{array}$ & $\begin{array}{r}(0.019) \\
* * * 6.421 \\
(0.006)\end{array}$ \\
\hline $1 \%$ rise in Hindu exp. reduces conflict by & $0.1 \%$ & $2.1 \%$ & $2.3 \%$ & $5.2 \%$ & $4.2 \%$ & $6.0 \%$ \\
\hline $1 \%$ rise in Muslim exp. raises conflict by & $0.9 \%$ & $2.5 \%$ & $3.7 \%$ & $4.2 \%$ & $6.6 \%$ & $6.6 \%$ \\
\hline Log-Likelihood/Adjusted $R^{2}$ & -730.84 & -149.57 & -193.27 & -128.76 & 0.402 & 0.435 \\
\hline Observations & 126 & 132 & 126 & 132 & 126 & 132 \\
\hline
\end{tabular}

Table 4. The Effect of Hindu and Muslim Expenditures on Regional Conflict: FE regressions with Poisson, Negative Binomial and OLS, respectively (variations). Sources and Notes. Varshney-Wilkinson dataset on religious riots, National Sample Survey 38th, 43rd and 50th rounds. All counts over a five-year period starting immediately after the expenditure data. Robust standard errors clustered by region; corresponding $p$-values in parentheses. Controls for population, religious polarization, literacy rate, urbanization rate, Gini coefficients for Hindus and Muslims and time dummies included in all regressions. *significant at $10 \% * *$ significant at $5 \% * * *$ significant at $1 \%$.

4.5.3. Politics. Our basic empirical specification does not include a satisfactory variable that captures the ambient political climate, which might influence Hindu-Muslim violence. In particular, the period of our study coincides with the rise of Hindu politics in many parts of India. A useful indicator for this is the strength of the Bharatiya Janata Party (BJP) in the region. The BJP is a political party that is traditionally associated with a platform of respect for "Hindu values" and the creation of a State based on those values. We use "BJP share", the fraction of Lok Sabha (national level parliament) seats in the region that is held by that Party.

Given that politics plays a major role in determining the extent of Hindu-Muslim rioting in India (see, e.g., Wilkinson (2004)), we can ask if our findings are merely a reflection of the effect that the BJP's presence in a region has on regional violence.

In Table 5, we report some results for main measure of conflict, namely, casualties (see in particular, column 2). The basic finding that Muslim expenditures significantly and positively affect conflict, while Hindu expenditures exhibit (if anything) an opposite effect, remains entirely unaltered. The coefficient on BJP share is mostly not significant and the sign varies across specifications. To address the concern that more local political factors (which are not captured by the share of the BJP in national parliamentary seats) may influence the pattern of riots, we create an additional control: the share of votes obtained by the BJP in state-level electoral districts within a region. ${ }^{23}$

\footnotetext{
${ }^{23}$ This variable is positively correlated with BJP's share in parliamentary seats (correlation coefficient is about 0.65 ).
} 


\begin{tabular}{|c|c|c|c|c|c|}
\hline & Exp. Ratio & $\begin{array}{c}{[2]} \\
\text { Politics }\end{array}$ & $\begin{array}{c}{[3]} \\
\text { Urban }\end{array}$ & $\begin{array}{c}{[4]} \\
\text { Urban }\end{array}$ & $\begin{array}{c}{[5]} \\
\text { Urban }\end{array}$ \\
\hline Hindu per-capita expenditure & & $\begin{array}{r}* * *-6.825 \\
(0.003)\end{array}$ & $\begin{array}{r}* *-5.096 \\
(0.024)\end{array}$ & & \\
\hline Muslim per-capita expenditure & & $\begin{array}{r}* * * 4.668 \\
(0.001)\end{array}$ & $\begin{array}{r}* 3.617 \\
(0.056)\end{array}$ & & \\
\hline Muslim-Hindu exp. ratio & $\begin{array}{r}* * * 4.783 \\
(0.000)\end{array}$ & & & $\begin{array}{r}* * 3.772 \\
(0.042)\end{array}$ & $\begin{array}{r}* 2.521 \\
(0.090)\end{array}$ \\
\hline Per-capita expenditure & $\begin{array}{r}-3.356 \\
(0.208)\end{array}$ & & & $\begin{array}{r}-2.477 \\
(0.182)\end{array}$ & $\begin{array}{l}-2.911 \\
(0.167)\end{array}$ \\
\hline \% Lok Sabha held by BJP & & $\begin{array}{l}-0.030 \\
(0.965)\end{array}$ & $\begin{array}{r}0.915 \\
(0.144)\end{array}$ & $\begin{array}{l}0.928 \\
(0.152)\end{array}$ & $\begin{array}{l}0.118 \\
(0.878)\end{array}$ \\
\hline Literacy rate & Y & $\mathrm{Y}$ & $\mathrm{N}$ & $\mathrm{N}$ & $\mathrm{Y}$ \\
\hline Primary education completion rate & $\mathrm{N}$ & $\mathrm{N}$ & $\mathrm{Y}$ & Y & $\mathrm{N}$ \\
\hline Urbanization rate & Y & $\mathrm{Y}$ & $\mathrm{N}$ & $\mathrm{N}$ & $\mathrm{N}$ \\
\hline $1 \%$ rise in Muslim-Hindu exp. ratio raises conflict by & $4.9 \%$ & & & $3.8 \%$ & $2.5 \%$ \\
\hline $1 \%$ rise in Hindu exp. reduces conflict by & & $6.5 \%$ & $4.9 \%$ & & \\
\hline $1 \%$ rise in Muslim exp. raises conflict by & & $4.8 \%$ & $3.7 \%$ & & \\
\hline Log-Likelihood/Adjusted $R^{2}$ & $-3,318.69$ & $-3,357.20$ & $-3,064.43$ & $-3,028.97$ & $-3,735.57$ \\
\hline Observations & 129 & 129 & 123 & 123 & 123 \\
\hline
\end{tabular}

Table 5. The Effect of Hindu and Muslim Expenditures on Regional Conflict: Poisson Fixed Effects regressions (Robustness). Sources and Notes. Varshney-Wilkinson dataset on religious riots, National Sample Survey 38th, 43rd and 50th rounds. All counts over a five-year period starting immediately after the expenditure data. Dependent variable in all columns is Casualties (= Killed + Injured). Robust standard errors clustered by region; corresponding $p$-values in parentheses. Columns (3) - (5) uitlize only urban households. Controls for population, religious polarization, Gini coefficients for Hindus and Muslims and time dummies included in all regressions. *significant at $10 \% * *$ significant at $5 \% * * *$ significant at $1 \%$

This additional control makes no difference to the results; also, it is not significant in any of the specifications. $^{24}$

4.5.4. Urban Conflict. Hindu-Muslim riots are primarily an urban phenomenon; rural India is witness to fewer cases of religious riots. One way to deal with this situation is to restrict attention to urban households in our NSS expenditure rounds. We do so, and the findings are presented in columns 3-5 of Table 5. The results are in line with what we have obtained earlier, as the different specifications in that table show.

4.5.5. Different Lags. Our main specification relates Muslim and Hindu expenditures "today" to subsequent conflict, or more precisely, to a five-year aggregate of conflict starting the following year. It is clear that some degree of lagging is necessary, as there are effects running the other way in contemporaneous correlations, which is an issue that we return to in Section 5.1. At the same time, it is a safe presumption that our effect should die out with very long lags. It is easy enough

\footnotetext{
${ }^{24}$ See Online Appendix for detailed results.
} 


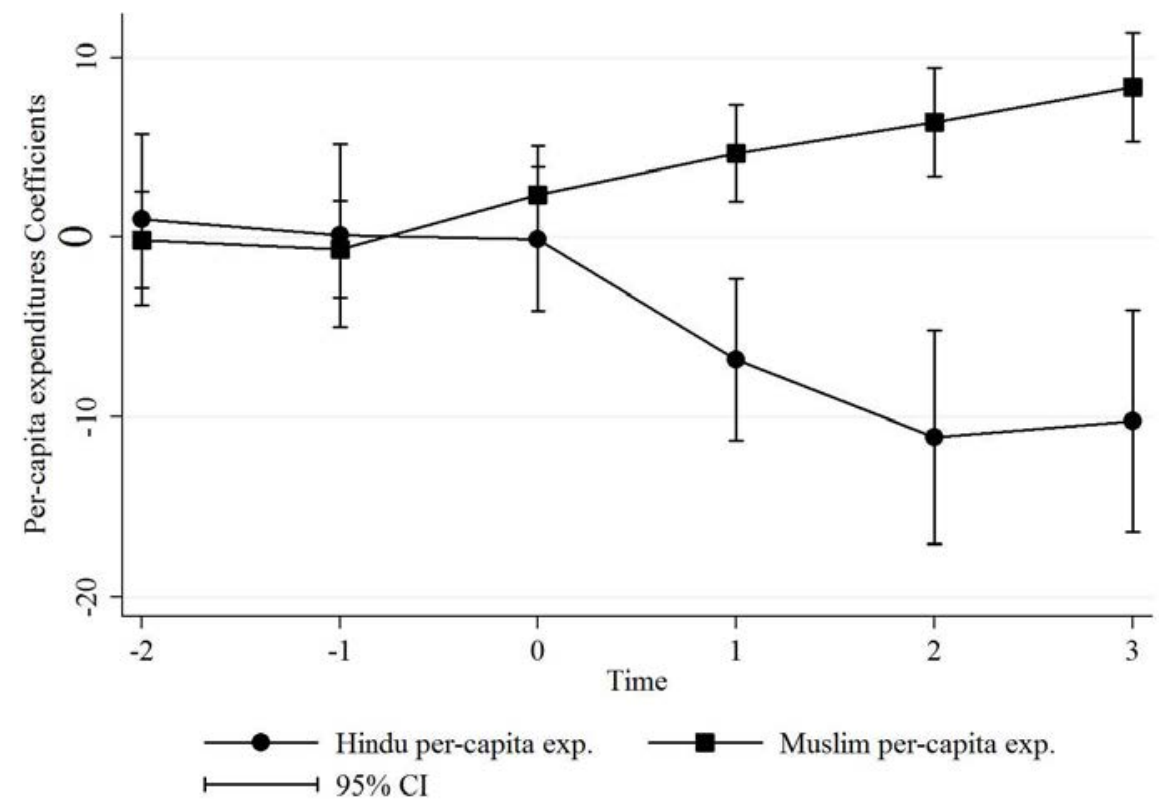

Figure 5. Different LAG STRUCTURES. The coefficients on Hindu and Muslim per-capita expenditures have been plotted against "time" which goes from -2 to 3 . The $95 \%$ confidence intervals around each coefficient have also been plotted.

to explore the effects of different lag structures on our regressions. That is, we match the three expenditures rounds with different 5-year periods of conflict that start with $n$ years into the future.

Detailed regressions are collected in the Online Appendix, but a visual depiction of the results is to be found in Figure 5, which reports on $n=-2,-1,0,1$ (our baseline case), 2 and 3 . The coefficients of the per-capita expenditures (Hindu and Muslim, separately) have been plotted with respect to "time" $(n)$. Observe that "contemporaneous conflict" ${ }^{25}(n=-2)$ appears to be negatively related to Muslim expenditures. As the lag is increased, the sign switches and turns positive. For lags larger than the ones we have chosen, the positive relationship diminishes and then any association between the variables progressively disappears. These results testify to the robustness of our basic findings.

\section{CONCERNS}

We raise three concerns, and describe what we do to alleviate them.

5.1. Endogeneity. While we explicitly regress conflict over a five-year period on anterior Hindu and Muslim expenditure, the question of endogeneity needs to be addressed. Even though we connect expenditure change to conflict starting a year later, conflict may well be serially correlated. For instance, some regions do exhibit violence more persistently over time than others, and besides, there is truth to the aphorism that "violence begets violence". To be sure, the region-specific fixed

\footnotetext{
${ }^{25}$ It is contemporaneous in the sense that the 38th round (1983) is matched with conflict during 1981-85, the 43rd round (1987-88) is matched with conflict during 1986-90 and the 50th round (1993-94) is matched with conflict during 1991-1995.
} 
effects are meant to capture the time-invariant features of the region which make it violence-prone. But of course, the effects that we're referring to are not generally time-invariant.

If conflict starting a year later is highly correlated with conflict today, there is effectively the possibility of reverse causation. But Section 2 makes it clear that conflict destroys Muslim property and wealth, and therefore reduces Muslim expenditure; see, e.g., Engineer (1984, 1994), Rajgopal (1987), Bagchi (1990), Khan (1992), Thakore (1993), Brass (1997), Das (2000), Engineer (1994), and the excellent summary of these and others in Wilkinson (2004). That the impact is negative is not very surprising as Muslims are a minority and happen to be poorer on average than their Hindu counterparts. It stands to reason that they would be less able to protect their lives and property in the event of a religious riot. However, the lagged relationship we obtain between Muslim expenditure and conflict in every one of the tables so far is just the opposite.

In short, the particular concern of reverse causation appears to runs the other way.

But the problem could be more subtle. Consider episodes of conflict followed by periods of relative quiescence. Suppose conflict depresses Muslim income. In the quiet period that follows, incomes would recover. If conflict flares up again along the violence-peace-violence cycle, that might generate a situation in which Muslim expenditures are positively correlated with future conflict. To be sure, such an argument, even without the empirical resolution we attempt below, rests on a somewhat delicate conceptual foundation. For expenditures to revert to pre-conflict levels, conflict must be temporary. Yet, for those expenditures to be correlated with (without causally influencing) $f u$ ture conflict, current and future conflict must be positively correlated. The greater this correlation, the less space there is for the mean-reversion to occur to begin with. But the possibility exists.

The omitted variable problem is of course, quite general, and there are possibly several factors that would affect both group incomes and conflict. An important example is the elite funding of conflict, particularly by inflows from the Gulf countries. To some extent, overall changes in Gulf fortunes are subsumed in the time dummies, but not to the extent that different Indian regions are differentially represented in the Gulf. Because remittances also flow for peaceful purposes, Muslim expenditures (which presumably include the effect of those remittances) could be correlated with Gulf funding for other, conflictual objectives.

To address these issues, we undertake two separate exercises, with the second building on the first. These are to be viewed as explorations that add to the overall weight of evidence. It would be an overstatement to assert that we account for all possible confounding factors (particularly, those due to omitted variables) and hence the results should be interpreted with appropriate circumspection.

5.1.1. 2SLS With Hindu and Muslim Income Indices. We begin with a broad classification of occupational groupings, and then use the NSS data on expenditures (by occupation) to form proxies of national average returns for Hindus and Muslims in each occupational class. For each religion, construct the weighted average of these returns, with weights given by the regional employment share over occupational groups. That generates an "income index" for each region and each religion. Changes in occupational composition at the regional level, coupled with changes in national returns by occupation, will affect these indices. We use them as instruments for Hindu and Muslim expenditures. Specifically, we take the ratio of the Muslim index to the Hindu index and use this as an instrument for the ratio of Muslim to Hindu expenditures at the regional level. 


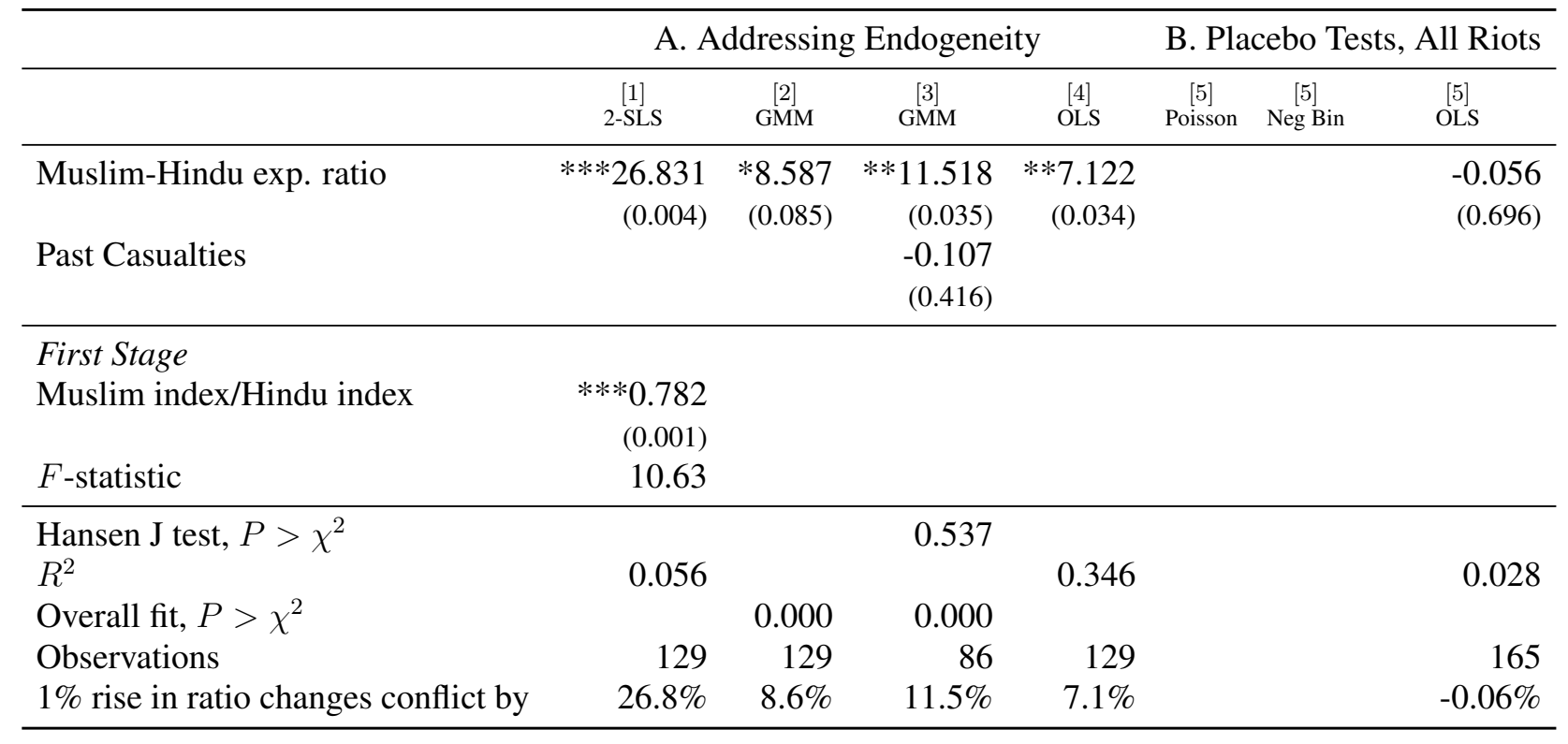

Table 6. Addressing Endogeneity, and Placebo Tests. Sources and Notes. Varshney-Wilkinson dataset on religious riots, National Sample Survey 38th, 43rd and 50th rounds; Govt. of India dataset on crime. All counts over a five-year period starting immediately after the expenditure data. Dependent variable is Casualties (=killed+injured). Columns 1-4 addresses endogeneity concerns. Column 1 reports the 2SLS specification with the first-stage regression coefficient on the IV reported below. Columns 2 and 3 utilize GMM specifications following Blundell and Bond (1998). Column 4 is the corresponding OLS specification (for comparison). Columns 5-7 report placebo test results for "All Riots," which are casualties based on the Government of India dataset on crime and hence contains numbers for all kinds of riots (not necessarily Hindu-Muslim riots). Robust standard errors clustered by region; corresponding $p$-values in parentheses. Controls for population, religious polarization, literacy rate, urbanization rate, Gini coefficients for Hindus and Muslims and time dummies included in all regressions. *significant at $10 \% * *$ significant at $5 \% * * *$ significant at $1 \%$

In short, we exploit the fact that Muslims and Hindus are concentrated differently over occupational classes. Presumably, such differential concentration stems from their specialization - over time - in different activities, their acquisition of skills and so on. For instance, an occupational class such as "Manufacture of Leather and Leather Products" has a disproportionate share of Muslims — in relation to their population numbers - and this is true across all the different time periods. To limit the potential for conflict to influence the occupational structure, we employ a rather broad partition of occupations. We use a total of 18 broad-brush sectors. ${ }^{26}$ That is, just 18 sectors are used to partition the entire labor force of India.

\footnotetext{
${ }^{26}$ The 18 sectors are: (1) Agricultural Production and Plantations, (2) Livestock Production, (3) Fishing, (4) Mining and Quarrying (Coal; Crude Petrol and Natural Gas; Metal Ore; Other), (5) Manufacture of Food Products and Inedible Oils, (6) Manufacture of Beverages, Tobacco and Tobacco products, (7) Manufacture of Textiles (Cotton; Wool, Silk, Artificial; Jute, Veg. Fibre; Textile Products), (8) Manufacture of Wood and Wooden Products, (9) Manufacture of Paper, Paper Products, Publishing, Printing and Allied Industries, (10) Manufacture of Leather, and of Leather and Fur Products, (11) Manufacture of Rubber, Plastic, Petroleum, Coal; Chemicals and Chemical Products, (12) Manufacture of Non-Metallic Mineral Products, (13) Basic Metal and Alloy Industries, (14) Manufacture of Metal Products and Parts, except Machinery and Transport Equipments, (15) Manufacture of Machinery, Machine Tools and Parts except Electrical Machinery, (16) Manufacture of Electrical Machinery, Appliances, Apparatus and Supplies and Parts, (17) Manufacture of Transport Equipments and Parts and (18) Other Manufacturing Industries.
} 
Column 1 in Table 6 presents the 2-SLS result for "casualties"; the corresponding OLS regression is reported in column 4 for ease of comparison. We report on other dependent variables such as "killed" and "outbreak" in the Online Appendix. Observe that the coefficient on the instrumented Muslim-Hindu expenditure ratio variable is positive and significant like in the OLS regression. However, the magnitudes of the two are statistically different. ${ }^{27}$ A $1 \%$ increase in the MuslimHindu expenditure ratio in a region raises casualties by $7.1 \%$ in the OLS FE model and by $26.8 \%$ in the 2-SLS specification. This latter effect is extremely large. While we accept that the 2-SLS estimates suggest that overall impact of economic factors on conflict is substantive, we would interpret the difference in magnitudes with real caution given that our sample size is limited. (See also the discussion on the GMM estimates below.)

5.1.2. GMM With Lagged Conflict and Income Indices. To explicitly allow for the possibility that past conflict might affect expenditures, we turn to the linear system GMM estimation procedure for dynamic panels suggested by Arellano and Bover (1995) and further developed by Blundell and Bond (1998). This estimation method recognizes the fact that current expenditures may be affected by previous conflict, so that expenditures, while predetermined, are not strictly exogenous. The idea is to use lagged expenditures as instruments for current expenditures after first-differencing (to eliminate unobserved fixed effects). Using this procedure a two-step system GMM estimator is developed based on appropriate moment conditions for both sets of equations - in first-differences and in levels. ${ }^{28}$ In addition, we include the Hindu and Muslim income indices described above in the set of instruments.

Moreover, this method is designed to provide consistent estimates for dynamic panels which include a lagged dependent variable as a regressor for short panels ( $N \rightarrow \infty$ while $T$ is fixed). Table 6 contains some results based on this estimation procedure. In the columns 2 and 3 of this table, we report results for the dependent variable casualties; in column 3 , we control for past levels of violence, thereby exploiting the full advantages of the system GMM estimation procedure. In each specification, the (robust) standard errors are based on the two-step GMM estimation method with bias-correction as proposed by Windmeijer (2005). The small $p$-values for the measure of overall fit (columns 2-3) are reassuring, as is the large $p$-value associated with the Hansen J-test for overidentification (column 3).

The coefficient estimates from the GMM regressions are closer to the OLS estimates in relation to the 2-SLS ones. In particular, a $1 \%$ increase in the Muslim-Hindu expenditure ratio in a region raises casualties by $8.6 \%$ (and $11.5 \%$ when directly controlling for past conflict) according to the GMM estimates.

5.2. Religious Rioting Versus General Rioting. It might be argued that a rise in Muslim expenditure (controlling for Hindu expenditure), or more generally a rise in the ratio of Muslim to Hindu expenditures, is just a proxy for overall Hindu stagnation, which could be associated with an increase in social unrest quite generally, and not just in Hindu-Muslim conflict. This argument would maintain that a concomitant rise in Hindu-Muslim conflict is just a by-product of this overall uptick in social unease, and could therefore not be interpretable as directed violence against a specific community.

\footnotetext{
${ }^{27}$ The difference in the coefficients is significant at the $95 \%$ level.

${ }^{28}$ See Cameron and Trivedi (2005) and Roodman (2006) for a detailed formal exposition.
} 
One can test this hypothesis in many ways. We do so by using the Government of India dataset on Crime in India, which has data on "all riots". That would presumably include but not be limited to Hindu-Muslim riots. ${ }^{29}$ Though Hindu-Muslim riots must form an important component of "all riots", it is by no means the dominant component. There are numerous sources of unrest in a country as culturally diverse as India. Examples include caste conflict (between upper and lower caste Hindus), Maoist insurgencies (often taking the form of a class struggle), separatist uprisings (in the forms of ethnic groups demanding an "autonomous state": Bodoland, Gurkhaland, Telengana, etc.), conflicts over land, and all sorts of political clashes.

We run a variety of specifications to evaluate this argument. The Online Appendix contains a detailed table. We report the specification using Muslim-Hindu expenditure ratios in columns 5-7 of Table 6. Note that an increase in this ratio is not associated with a increase in overall social unrest. In fact, the null hypothesis that the effect of expenditure ratio on "all riots" is the same (in elasticity terms) as that on religious riots is rejected at the 95\% level ( $p$-value $=0.013)$.

5.3. Muslim Incomes and the Funding of Violence. We use the theory in Section 3 to interpret the empirical findings. Recall that we describe a two-group model in which aggressors in each group can initiate a conflict with victims in the other group. We've argued that a balanced increase in the incomes of a group should lead to unambiguously higher levels of attacks being perpetrated against them. (There is more to loot, or greater urgency to exclude, or more reasons to hate.) In contrast, an increase in incomes reduces attacks perpetrated by that group. (The opportunity cost of violence increases.) The theory therefore permits the following interpretation of our empirical results. The fact that Muslim expenditures display a strong and positive connection with conflict, while Hindu incomes have just the opposite effect, allows us to suggest that Hindu groups have been more responsive to economic considerations in precipitating Hindu-Muslim violence in postIndependence India.

This interpretation is in line with the Indian experience. Section 2 refers to several case studies which describe a Hindu reaction to what they perceive as the invasion of their occupational or entrepreneurial turf by Muslims. It is possible that in other situations the opposite may have been true, but as we've already noted, Muslims come off far worse, on average, in conflictual encounters. This is not surprising, as Indian Muslims constitute a minority. At the same time, it is impossible to be sure from the case studies alone that one group has engaged in a more systematic perpetration of economic violence than the other. Most incidents follow earlier incidents in a cycle of retribution, and no incident can be viewed in isolation. The question of whether one group has engaged "more systematically" in violence cannot be answered through case studies alone, though these provide valuable indicative information. We view our results as adding to this body of evidence.

One counterargument to our interpretation is that the positive impact of Muslim expenditures on violence stems from Muslim, not Hindu aggression. Specifically, rising Muslim incomes make it easier to fund conflict, outweighing the negative opportunity cost effects of direct participation. That, too, would generate a positive relationship between the income of an aggressor group and subsequent conflict.

While hard empirical information on the funding of religious conflict does not appear to be available, it is reasonable that financial resources play a role in organized violence. The question is

\footnotetext{
${ }^{29}$ It is important to note that this dataset does not have specific information regarding Hindu-Muslim violence.
} 
whether it is this phenomenon that lies behind the correlations we do observe. The fact that the Hindu coefficient is negative means that if "funding effects" are responsible for what we see, they are somehow observed only for Muslim groups while the effect is entirely obliterated and reversed for Hindu groups. That is possible, but in light of the fact that Muslims are by far the larger losers in outbreaks of violence, the simultaneous conjunction of all these explanations - Muslims fund conflict, Hindus don't, Hindus are on average richer, Muslims are by far the bigger per-capita losers - appears unlikely.

Next, there are good reasons to suppose that "funding effects" will not heighten conflict in situations of balanced growth in group incomes, which is precisely the focus of our empirical exercise. To see this, recall the analysis from Section 3, and reconstruct the attack function to include two alternatives: direct participation in violence, and the funding of violence. These two alternatives are affected very differently by an increase in income. Direct participation is reduced (the opportunity cost of time goes up), while the funding of violence is increased (the opportunity cost of financial contributions is lowered). ${ }^{30}$ To capture the latter effect we now endow the attacker with a strictly concave utility function $u$ on consumption $x$, which we take to have constant elasticity: $u(x)=x^{1-\sigma} /(1-\sigma)$ for $\sigma>0 .^{31}$

As before, suppose that a potential aggressor with income $z$ must decide whether or not to inflict violence on an individual with income $y$. He can do so via direct participation, which involves a time opportunity cost of $t$. Or he can fund an equivalent amount of violence by paying for the opportunity cost of someone else's time at the rate of $f$. The net return to "participatory violence" is then

$$
P(z)=(1-p) u([1-t] z)+p u([1-t] z+\lambda y),
$$

while the net return to monetary of "funded violence" is given by

$$
M(z)=(1-p) u(z-f)+p u(z-f+\lambda y)
$$

where, just as we had earlier, $\lambda y$ stands for the economic equivalent of the spoils from a victim with income $y$ in the event of a successful attack.

The question is what a balanced growth in group incomes does to the funding requirement $f$. If violence is principally carried out by individuals from the same group as the aggressor, then $f$ must rise in roughly proportional fashion to $z$. We then have

PROPOSITION 2. A balanced increase in group incomes that causes both the funding requirement $f$ and all aggressor incomes $z$ to rise in equal proportion, must reduce attacks perpetrated by members of that group.

An increase in $z$ raises the opportunity cost of time, thereby reducing participatory violence. As for funded violence, a proportionate increase of $f$ with $z$ keeps the opportunity cost of violence constant as a proportion of $z$. At the same time, the looting of a victim with the same income $y$ appears less attractive in relative terms. So in both cases, violence perpetrated by the group must decline. (The formal arguments rely on the constant-elasticity formulation of utility; see Appendix. In addition, the online Appendix integrates this extension fully into the basic model of Section 3.)

\footnotetext{
${ }^{30}$ Esteban and Ray (2011) develop these observations to connect within-group inequality to violence.

${ }^{31}$ When $\sigma=1, u$ is logarithmic.
} 


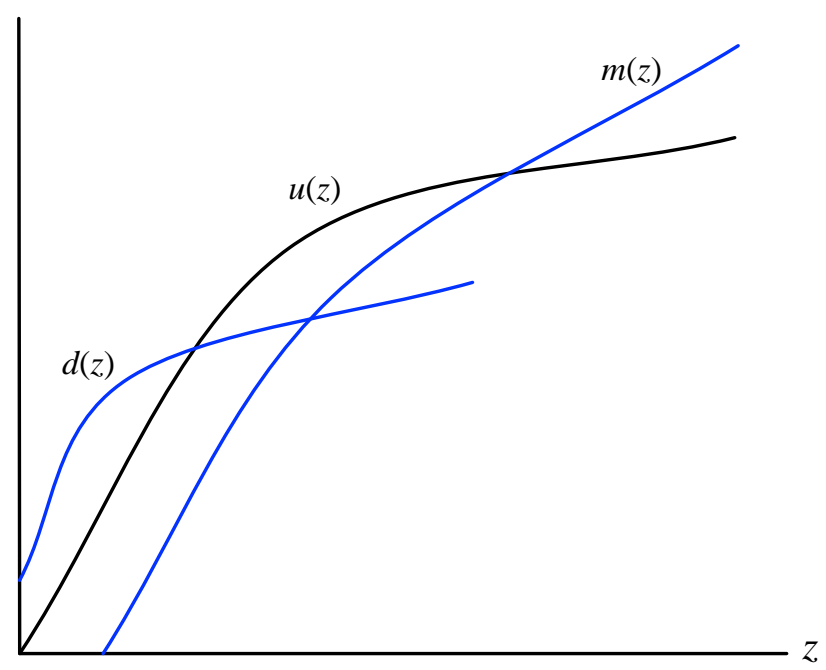

Figure 6. PARTICIPATION AND FUnDING: LOW AND High InCOMES

Faced with Proposition 2, it is still possible to assert either that paid attackers are not from the same religious group, or that funding pays for non-human inputs into violence. ${ }^{32}$ In either case $f$ will not change (or won't change in proportion) when $z$ does. We would actually defend the claim that same-group human input is, in fact, central to funded violence, but we can go a step further by considering an implication of this contrary viewpoint: that the funding effect must be stronger at higher levels of income.

Proposition 3. Suppose that both funding and direct participation can be used to generate a violent attack, and that $f$ does not change with $z$. Then:

(a) If funded violence is preferred to participatory violence at income $z$, the same preference is maintained for all $z^{\prime}>z$.

(b) If funded violence is preferred to peace at income z, then it is preferred for all higher incomes.

(c) If participatory violence is preferred to peace at income $z$, then it is preferred for all lower incomes.

Figure 6 illustrates the proposition, which we prove formally in the Appendix. Payoff from participatory violence dominates all other payoffs at low incomes, while payoffs from funded violence dominate at high incomes. This makes perfect sense once we consider the opportunity costs of time and money. It follows that when the distribution of income is concentrated on relatively low incomes, an increase in aggressor income is likely to result in a decline in violence, as individuals move from the first zone of participatory violence into the second zone of peace. The opposite effect holds when incomes are relatively high: individuals will move from the peace zone into the funded violence zone.

That suggests a test: if funded violence drives the positive relationship between Muslim expenditures and subsequent conflict, then Proposition 3 applies, and the positive effect should be stronger in richer regions. Figure 7 provides one way of examining this relationship. We define a region

\footnotetext{
${ }^{32}$ The latter argument is analogous to that carried out for the protection function in Section 3.
} 


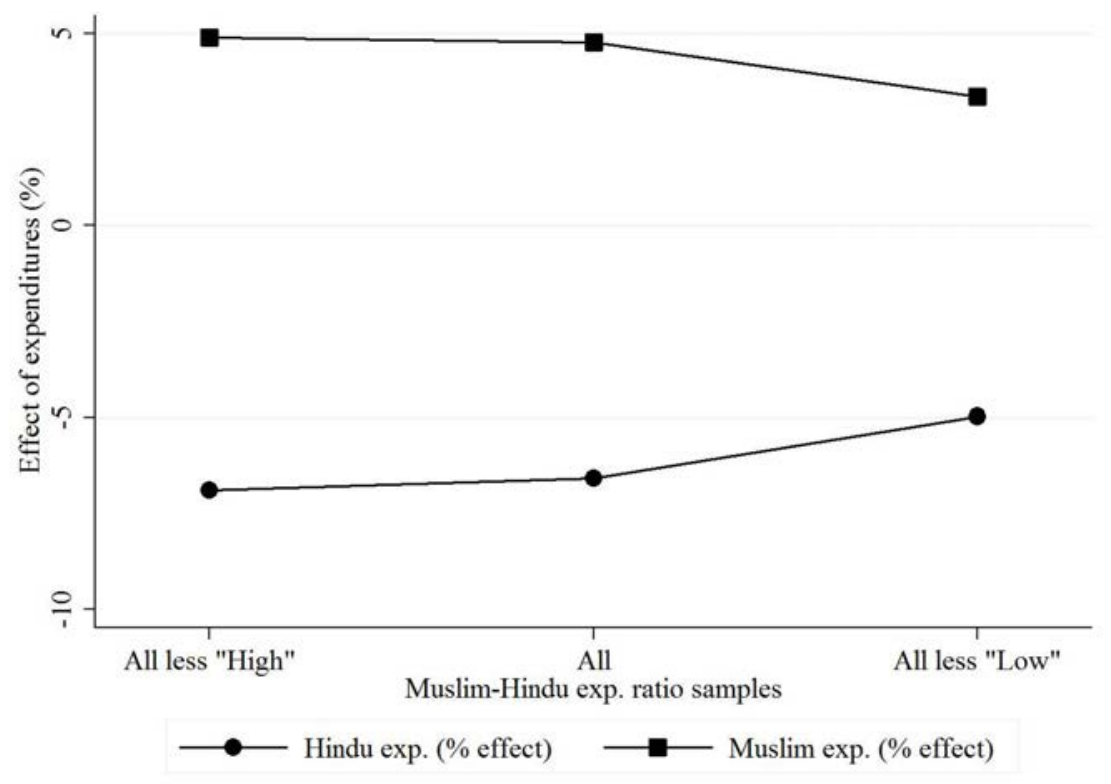

Figure 7. Different Regional samples. The (\%) effect on conflict of a $1 \%$ change Hindu and Muslim per-capita expenditures have been plotted on the vertical axis for 3 different regional samples: All regions, All less "low" and All less "High". We define a region to be "low" if Muslim/Hindu expenditure ratios in that region are systematically lower than the national average for each of the three time periods ("high" is defined analogously).

to be "low" if Muslim/Hindu expenditure ratios in that region are systematically lower than the national average for each of the three time periods. In similar fashion, we may define the "high" regions. Figure 7 plots the effect on casualties (in \% terms) of a 1\% change in Hindu and Muslim expenditures for three different regional samples: all regions, all less "high" regions and all less "low" regions. 33

Figure 7 shows that there are no discernible differences in the effect across the three sets of regions. If we believe the funding argument, we must also accept the conclusion that the poorer regions are funding conflict to the same degree as the richer regions, even after controlling for inequality, an observation that runs up against Proposition 3.

\section{SuMmARY AND CONCLUDING REMARKS}

Our empirical investigations yield a central result, which we explore from a number of angles. An increase in Muslim well-being, measured by per-capita Muslim expenditures, leads to a large and significant increase in religious conflict in the short to medium run; specifically, in a five-year aggregate of conflict starting from the very next year (relative to the expenditure year). In contrast, an increase in Hindu well-being has either an insignificant or a negative effect on future conflict. We obtain this finding using a three-period Indian panel with region and time effects employed throughout.

\footnotetext{
${ }^{33}$ We take this approach so as to preserve a relatively large number of regions in each subcase, otherwise we quickly run out of statistical power. We have tried several alternative specifications with no essential difference in the results.
} 
This result is robust along a number of dimensions. It is robust to different measures of religious conflict: numbers killed, numbers killed+injured, or coarser outcomes such as the number of riots. It persists whether we use the absolute values of Hindu and Muslim expenditures, or their ratio. It is robust to the inclusion of several controls, such as literacy rates and the degree of urbanization. It is robust to the inclusion of political variables, such as the share of the BJP in total Lok Sabha seats.

Our finding is also robust to the use of alternative lag structures, as long as we focus on conflict following the change in expenditure. That isn't surprising, as the contemporaneous relationship between conflict and Muslim per-capita expenditure is negative, a phenomenon well-documented in studies that show that Muslims suffer disproportionately from religious violence in India. In the light of this fact, it is remarkable that the association between Muslim per-capita expenditures and subsequent conflict is precisely reversed, and turns positive. Indeed, a rise in Muslim percapita expenditures seems to increase conflict starting from the very next year and for some years onwards. Relatedly, we discuss the question of endogeneity in some detail. We instrument for the ratio of Muslim to Hindu expenditures using an index that we construct from data on occupational structure. Next, we use two-stage GMM estimation with lagged expenditure and our occupational income indices as joint instruments. In addition, we introduce controls for current conflict. In all of these exercises, our results persist. As a final check, we show that a parallel investigation for all riots in India - which include but are by no means restricted to Hindu-Muslim riots - show no systematic relationship between Muslim per-capita expenditures and conflict. The relationship we uncover is specific to riots between two religious groups, and not conflict in general.

Our preferred interpretation is based on the theory outlined in Section 3. But that theory can be placed in a context. There are many case studies in which attacks on the Muslim community can be traced to various forms of Muslim economic empowerment; see the references in Section 2. Moreover, we've shown in Section 5.3 that alternative theories, such as conflict created by the funding of Muslim groups, are not consistent with the available empirical evidence.

An ongoing (and not entirely coolheaded) conversation is invariably present in India over which side is largely "at fault" when religious violence breaks out. This debate, as one might imagine, is politically and emotionally charged, and the "evidence" offered up in one reading is predictably challenged by another. Some incidents, such as the demolition of the Babri Masjid in 1992 or the attacks in Mumbai in 2008, are relatively clear-cut in the immediate identity of their initiators, though - to be sure - their antecedents may go back a long way. Other incidents can be traced to still earlier incidents along the well-worn trail of revenge and retribution, and there is no clear-cut perpetrator.

To some, the question of whether there is systematic perpetration by one group is a politically loaded question to which only an ideological answer is possible. No incident can be viewed in isolation, and it is easy enough to argue that a particular episode has roots that have been conveniently ignored by the ethnographer. Perhaps there is no such thing anyway as systematic perpetration "by one side".

But - while important - it is unclear that all conflict is driven by chicken-and-egg-like processes, with their original roots entirely lost in time. Those familiar with particular histories, such as the modern history of India, will know that there are group leaders on either side of the Hindu-Muslim conflict that have systematically attempted to take advantage of inter-group tensions. To understand 
whether one group has done so "more systematically" than the other is not just important from a policy perspective, it is crucial to our intellectual understanding of the politics of a society, and to the policies that one must adopt. It is also important to note that we uncover an asymmetry in the sensitivity or response of violence to economic change. It is indeed possible that such an asymmetry can be compatible with a symmetric level of "baseline" violence perpetrated by both groups.

Finally, we do not believe that a particular religious group is intrinsically more predisposed to the use of violence. In a parallel universe (or in another country) with a different social history and a different demography, the outcomes may well have been very different.

\section{REFERENCES}

André, C. And J-Ph. Platteau (1998), "Land Relations Under Unbearable Stress: Rwanda Caught in the Malthusian Trap," Journal of Economic Behavior and Organization 34, 1-47.

Arellano, M. AND S. Bond (1991), "Some tests of specification for panel data: Monte Carlo evidence and an application to employment equations." Review of Economic Studies 58: 277-97.

Arellano, M. AND O. Bover (1995), "Another look at the instrumental variables estimation of error-components models." Journal of Econometrics 68: 29-51.

A. Azeez And M. Begum (2009), "Gulf Migration, Remittances and Economic Impact," Journal of Social Sciences.

BAgCHI, A. (1990), "Predatory Commercialization and Communalism in India," in S. Gopal (ed), Anatomy of a Confrontation, New Delhi: Penguin.

BASAnT, R. (2012), "Education and Employment among Muslims in India: An Analysis of Patterns and Trends" W.P. No. 2012-09-03, Indian Institute of Management, Ahmedabad, India.

Blattman, C. And E. Miguel (2010), “Civil War,” Journal of Economic Literature 48, 3-57.

Blundell, R., AND S. BOND (1998), "Initial conditions and moment restrictions in dynamic panel data models." Journal of Econometrics 87: 115-143.

Bohr, A. And S. CRISP (1996), “Kyrgyzstan and the Kyrgyz,” in G. Smith (ed.), The Nationalities Question in the Post-Soviet States, New York and London: Longman Publishers.

Cameron, A.C. And P.K. Trivedi (2005), "Microeconometrics: Methods and Applications." Cambridge: Cambridge University Press.

Chandhoke, N. (2009), “Civil Society in Conflict Cities: The Case of Ahmedabad,” Crisis States

Research Centre Working Papers Series 2, 64. Crisis States Research Centre, London School of Economics and Political Science.

Collier, P. And A. Hoeffler (1998), "On Economic Causes of Civil War," Oxford Economic Papers 50, 563-573.

Collier, P. And A. Hoeffler (2004), "Greed and Grievance in Civil War," Oxford Economic Papers 56, 563-595. 
DAS, S. (2000), “The 1992 Calcutta Riots in Historical Continuum: A Relapse into 'Communal Fury'," Modern Asian Studies 34, 301.

Dube, O. And J. VArgas (2013), "Commodity Price Shocks and Civil Conflict: Evidence from Colombia," forthcoming, Review of Economic Studies.

Duflo, E. AND R. PANDE (2007), “Dams, Quarterly Journal of Economics 122, 601-646.

Engineer, A. (1984), "The Causes of Communal Riots in the Post-Partition Period in India," in A. Engineer (ed.), Communal Riots in Post-Independence India, Hyderabad: Sangam Books, 33-41.

Engineer, A. (1994), “Communal Violence in Kanpur,” Economic and Political Weekly, February $26,473-474$.

Esteban, J. And D. RAY (1999), “Conflict and Distribution,” Journal of Economic Theory 87, 379-415 (1999).

Esteban, J. And D. RAy (2007), "Polarization, Fractionalization and Conflict," Journal of Peace Research 45, 163-182 (2007).

Esteban, J. And D. Ray (2008), “On the Salience of Ethnic Conflict," American Economic Review 98, 2185-2202.

Esteban, J. And D. RAY (2011), “A Model of Ethnic Conflict,” Journal of the European Economic Association 9, 496-521.

FEARon, J. AND D. LAitin (2003), "Ethnicity, Insurgency, and Civil War," American Political Science Review 97, 75-90.

Field, E., Levinson, M., PAnde, R. And S. Visaria (2008), "Segregation, Rent Control, and Riots: The Economics of Religious Conflict in an Indian City," American Economic Review (Papers and Proceedings).

Horowitz, D. (2000), Ethnic Groups in Conflict, Second Edition, University of California Press.

Horowitz, D. (2001), The Deadly Ethnic Riot, University of California Press.

Huber, J. AND L. MAYORAL (2013), “Inequality, Ethnicity and Civil Conict,” mimeo., Instituto de Análisis Económico, Barcelona.

IYER, L. AND Q-T. Do (2009), "Geography, Poverty and Conflict in Nepal," forthcoming, Journal of Peace Research.

JHA, S. (2013), “Trade, Institutions and Ethnic Tolerance: Evidence from India," forthcoming, American Political Science Review.

Khan, D. (1992), "Meerut Riots: An Analysis," in P. Kumar (ed.), Towards Understanding Communalism, Chandigarh: Centre for Research in Rural and Industrial Development, 465.

MahadeviA, D. (2002), "Communal Space over Life Space: Saga of Increasing Vulnerability in Ahmedabad," Economic and Political Weekly November 30, 4850-4358. 
Miguel, E., Satyanath, S. And E. Sergenti (2004), "Economic Shocks and Civil Conflict: An Instrumental Variables Approach, Journal of Political Economy 112, 725-753.

Montalvo, J. And M. Reynal-Querol (2005), "Ethnic Polarization, Potential Conflict, and Civil Wars," American Economic Review 95, 796-813.

Rajgopal, P. (1987), Communal Riots in India, New Delhi: Uppal Publishing House/Centre for Policy Research.

RAY, D. (2009), "Costly Conflict Under Complete Information," mimeo., Department of Economics, New York University.

Roodman, D. (2006), "How to do Xtabond2: An Introduction to Difference and System GMM in Stata." Stata Journal 9(1), StataCorp LP, 86-136

ThaKore, D. (1993), “The Burning of Bombay,” Sunday, January 24-30, 28-37.

VARShney, A. And STEVEn Wilkinson (2004). "Dataset on Hindu-Muslim Violence in India, Version 2." October 8, 2004.

Wilkinson, S. (2004), Votes and Violence: Electoral Competition and Ethnic Riots in India, Cambridge: Cambridge University Press.

WindMEIJER, F. (2005), "A finite sample correction for the variance of linear efficient two-step GMM estimators.” Journal of Econometrics 126: 25-51.

YAARI, M. (1969), “Some Remarks on Measures of Risk Aversion and on Their Uses," Journal of Economic Theory 1, 315-329.

\section{APPENDIX}

Proof of Observation 1. First we show that the protection function is downward-sloping. Recall that $d$ is chosen to minimize

$$
\alpha(\mu-\beta) p(d)+[c(d) / y]
$$

where $\mu-\beta>0$. Pick two values of $\alpha$, call them $\alpha_{1}$ and $\alpha_{2}$, with $\alpha_{2}>\alpha_{1}$. Let $d_{1}$ and $d_{2}$ be two corresponding minima. Certainly,

$$
\alpha_{1}(\mu-\beta) p\left(d_{1}\right)+\left[c\left(d_{1}\right) / y\right] \leq \alpha_{1}(\mu-\beta) p\left(d_{2}\right)+\left[c\left(d_{2}\right) / y\right]
$$

while at the same time,

$$
\alpha_{2}(\mu-\beta) p\left(d_{2}\right)+\left[c\left(d_{2}\right) / y\right] \leq \alpha_{2}(\mu-\beta) p\left(d_{1}\right)+\left[c\left(d_{1}\right) / y\right],
$$

Combining these two inequalities, we must conclude that

$$
\left(\alpha_{2}-\alpha_{1}\right)\left[p\left(d_{2}\right)-p\left(d_{1}\right)\right] \leq 0
$$

It follows that $p\left(d_{2}\right) \leq p\left(d_{1}\right)$, as required.

The fact that the attack function is (weakly) increasing is an immediate consequence of (2). It will be strictly increasing when the cdf $F$ is strictly increasing everywhere. 
Finally, the graphs of both functions can be made continuous by spreading individuals in different proportions over their optimal actions (in case the best-response is multi-valued somewhere). Moreover, the relevant endpoint conditions are met. So a unique equilibrium exists.

Proof of Proposition 2. Note that the condition for participatory violence is given by

$$
(1-p) \frac{([1-t] z)^{1-\sigma}}{1-\sigma}+p \frac{([1-t] z+\lambda y)^{1-\sigma}}{1-\sigma} \geq \frac{z^{1-\sigma}}{1-\sigma},
$$

and dividing through by $[(1-t) z]^{1-\sigma}$ on both sides, we get

$$
\frac{1-p}{1-\sigma}+p \frac{\left[1+\frac{\lambda y}{(1-t) z}\right]^{1-\sigma}}{1-\sigma} \geq \frac{1}{(1-t)^{1-\sigma}} .
$$

We see immediately from (3) that there exists a unique threshold value $z^{*}$ such that participatory violence is preferable to peace for $z<z^{*}$, while the opposite is true when $z>z^{*}$.

When $f$ is proportional to $z$, exactly the same observation goes through for funded violence. Simply define $t \equiv f / z$, and apply the previous argument.

Proof of Proposition 3. (a) Funded violence uses a payment of $f$ to achieve the same probabilistic result that participatory violence achieves for a payment of $t z$. It follows that the former will be preferred to the latter if and only if $z>f / t$.

(b) The proposition asserts that if funded violence dominates peace for some $z$, then it does so for all $z^{\prime}>z$. This is equivalent to the condition of nonincreasing global risk aversion; see Axiom $\mathrm{V}$ in Yaari (1969). By Remark 7 and the subsequent discussion on pp. 326-327, we see that decreasing absolute risk aversion (DARA) in the sense of Arrow implies Axiom V. But our utility function satisfies DARA.

(c) Follows from the same argument as in the proof of Proposition 2. 


\begin{tabular}{|c|c|c|c|c|c|c|c|}
\hline \multirow[t]{2}{*}{ State } & \multirow[t]{2}{*}{ Region } & \multicolumn{3}{|c|}{ Casualties } & \multicolumn{3}{|c|}{ M/H Exp. } \\
\hline & & Period I & Period II & Period III & Period I & Period II & Period III \\
\hline Andhra Pradesh & Coastal & 0 & 3 & 0 & 1.004507 & 1.091982 & .9764359 \\
\hline Andhra Pradesh & Inland Northern & 312 & 220 & 141 & 1.038641 & .9156198 & 1.064655 \\
\hline Andhra Pradesh & South Western & 8 & 0 & 0 & .9166893 & 1.052765 & 1.196671 \\
\hline Andhra Pradesh & Inland Southern & 0 & 3 & 0 & .9912738 & .8575357 & .8631487 \\
\hline Bihar & Southern & 16 & 38 & 31 & 1.069841 & .8966287 & .8629227 \\
\hline Bihar & Northern & 45 & 166 & 155 & .8955503 & .9364876 & .9712139 \\
\hline Bihar & Central & 1 & 443 & 1 & 1.14185 & .984996 & 1.072345 \\
\hline Gujarat & Eastern & 13 & 829 & 16 & .842355 & 1.277648 & 1.138291 \\
\hline Gujarat & Plains Northern & 1526 & 911 & 1 & 1.117543 & 1.045082 & .882774 \\
\hline Gujarat & Plains Southern & 311 & 174 & 0 & .8843232 & .8737228 & 1.00092 \\
\hline Gujarat & Dry Areas & 26 & 7 & 0 & 1.054092 & .9967834 & 1.002777 \\
\hline Gujarat & Saurashtra & 56 & 7 & 622 & .8979987 & .9043204 & .8817747 \\
\hline Haryana & Eastern & 0 & 6 & 0 & .9330744 & .9526062 & .7195345 \\
\hline Haryana & Western & 0 & 0 & 0 & .653703 & 1.174521 & .5173813 \\
\hline Karnataka & Coastal \& Ghat & 0 & 48 & 36 & .8412368 & 1.201041 & 1.45227 \\
\hline Karnataka & Inland Eastern & 50 & 2 & 12 & 1.189586 & .9304261 & .9984706 \\
\hline Karnataka & Inland Southern & 181 & 200 & 81 & .9829123 & .9992417 & 1.096229 \\
\hline Karnataka & Inland Northern & 69 & 180 & 106 & 1.057045 & .9818084 & .869728 \\
\hline Kerala & Northern & 0 & 6 & 0 & .8434259 & .8615004 & .8620393 \\
\hline Kerala & Southern & 17 & 36 & 0 & .9358429 & .871028 & 1.088838 \\
\hline Madhya Pradesh & Chattisgarh & 0 & 25 & 0 & 1.277899 & 1.407446 & 1.614995 \\
\hline Madhya Pradesh & Vindhya & 0 & 0 & 0 & .9776053 & 1.090256 & 1.155049 \\
\hline Madhya Pradesh & Central & 43 & 507 & 0 & .977567 & 1.032186 & .9767985 \\
\hline Madhya Pradesh & Malwa Plateau & 62 & 228 & 0 & 1.274306 & 1.123192 & .8642549 \\
\hline Madhya Pradesh & South Central & 0 & 0 & 0 & .9756939 & .9741977 & 1.134518 \\
\hline Madhya Pradesh & South Western & 34 & 34 & 0 & 1.119037 & 1.413961 & 1.221877 \\
\hline Madhya Pradesh & Northern & 0 & 0 & 0 & .7267752 & .9629654 & .9172089 \\
\hline Maharashtra & Coastal & 621 & 2447 & 51 & .9742841 & 1.171711 & .9900791 \\
\hline Maharashtra & Inland Western & 162 & 25 & 0 & .9499936 & .8866885 & .8947135 \\
\hline Maharashtra & Inland Northern & 136 & 47 & 165 & .7971309 & .7896825 & .9842166 \\
\hline Maharashtra & Inland Central & 197 & 20 & 44 & .9700853 & .8033 & .8699216 \\
\hline Maharashtra & Inland Eastern & 134 & 6 & 0 & 1.035705 & .7726147 & .7019697 \\
\hline Maharashtra & Eastern & 0 & 0 & 0 & .9955956 & 1.348744 & 1.151897 \\
\hline Orissa & Coastal & 0 & 62 & 0 & .965429 & 1.100203 & .8838249 \\
\hline Orissa & Southern & 0 & 0 & 0 & 2.282952 & 1.717748 & .9707198 \\
\hline Orissa & Northern & 0 & 0 & 0 & 2.758474 & 1.07864 & 1.375739 \\
\hline Punjab & Northern & 13 & 0 & 0 & 1.325563 & .819111 & .9253177 \\
\hline Punjab & Southern & 0 & 0 & 0 & .8700712 & .8409578 & .7445471 \\
\hline Rajasthan & Western & 6 & 37 & 0 & .9857437 & .8666831 & .839959 \\
\hline Rajasthan & North Eastern & 0 & 161 & 66 & .8458781 & .8425692 & .7995163 \\
\hline Rajasthan & Southern & 8 & 21 & 0 & 2.316313 & 2.172886 & .9456905 \\
\hline Rajasthan & South Eastern & 0 & 83 & 0 & 1.026613 & 1.090762 & .7404696 \\
\hline Tamil Nadu & Coastal Northern & 21 & 82 & 51 & 1.16093 & 1.05886 & 1.035249 \\
\hline Tamil Nadu & Coastal & 0 & 0 & 0 & 1.213718 & 1.238767 & 1.170456 \\
\hline Tamil Nadu & Southern & 0 & 43 & 1 & .6930835 & 1.060303 & .9730101 \\
\hline Tamil Nadu & Inland & 0 & 0 & 15 & .8313742 & 1.226216 & .9505917 \\
\hline Uttar Pradesh & Himalayan & 0 & 0 & 0 & .8449162 & .6477033 & .8109938 \\
\hline Uttar Pradesh & Western & 628 & 812 & 90 & .8156493 & .8381398 & .8111452 \\
\hline Uttar Pradesh & Central & 100 & 140 & 68 & .9139733 & .8625087 & 1.042183 \\
\hline Uttar Pradesh & Eastern & 235 & 103 & 59 & .989118 & 1.051022 & 1.073385 \\
\hline Uttar Pradesh & Southern & 0 & 0 & 0 & .9527379 & .9129332 & .7660533 \\
\hline West Bengal & Himalayan & 0 & 0 & 0 & .8492237 & .8596027 & .93025 \\
\hline West Bengal & Eastern Plains & 58 & 0 & 0 & .791344 & .8848535 & .9269146 \\
\hline West Bengal & Central Plains & 13 & 139 & 0 & .8389444 & .7647896 & .7248861 \\
\hline West Bengal & Western Plains & 0 & 9 & 0 & .9558726 & .951232 & .8094822 \\
\hline
\end{tabular}

Table 7. Regional level Descriptive Statistics: Sources and Notes. Varshney-Wilkinson dataset on religious riots, National Sample Survey 38th, 43rd and 50th rounds. Casualties=killed+injured. M/H Exp. = Muslim per-capita expenditure/ Hindu per-capita expenditure. 